\title{
Antimicrobial Stewardship: Fighting Antimicrobial Resistance and Protecting Global Public Health
}

This article was published in the following Dove Press journal:

Infection and Drug Resistance

\author{
Md Anwarul Azim \\ Majumder (1D' \\ Sayeeda Rahman (iD ${ }^{2}$ \\ Damian Cohall (D) \\ Ambadasu Bharatha $\mathbb{D D}^{\prime}$ \\ Keerti Singh (D)' \\ Mainul Haque $\mathbb{D D}^{3}$ \\ Marquita Gittens-St Hilaire $\mathbb{D}^{\prime}$ \\ 'Faculty of Medical Sciences, The \\ University of the West Indies, Cave Hill \\ Campus, Bridgetown, Barbados; ${ }^{2}$ School \\ of Medicine, American University of \\ Integrative Sciences, Bridgetown, \\ Barbados; ${ }^{3}$ Faculty of Medicine and \\ Defence Health, Universiti Pertahanan, \\ Nasional Malaysia (National Defence \\ University of Malaysia), Kuala Lumpur, \\ Malaysia
}

\begin{abstract}
Antimicrobial resistance (AMR) is a serious threat to global public health. It increases morbidity and mortality, and is associated with high economic costs due to its health care burden. Infections with multidrug-resistant (MDR) bacteria also have substantial implications on clinical and economic outcomes. Moreover, increased indiscriminate use of antibiotics during the COVID-19 pandemic will heighten bacterial resistance and ultimately lead to more deaths. This review highlights AMR's scale and consequences, the importance, and implications of an antimicrobial stewardship program (ASP) to fight resistance and protect global health. Antimicrobial stewardship (AMS), an organizational or system-wide health-care strategy, is designed to promote, improve, monitor, and evaluate the rational use of antimicrobials to preserve their future effectiveness, along with the promotion and protection of public health. ASP has been very successful in promoting antimicrobials' appropriate use by implementing evidence-based interventions. The "One Health" approach, a holistic and multisectoral approach, is also needed to address AMR's rising threat. AMS practices, principles, and interventions are critical steps towards containing and mitigating AMR. Evidence-based policies must guide the "One Health" approach, vaccination protocols, health professionals' education, and the public's awareness about AMR.
\end{abstract}

Keywords: antibiotics, antimicrobial resistance, multidrug-resistant, antimicrobial stewardship program, One Health, global health

\section{Introduction}

"As we gather more evidence, we see more clearly and more worryingly how fast we are losing critically important antimicrobial medicines all over the world." Dr. Tedros Adhanom Ghebreyesus, Director-General of the World Health Organization. ${ }^{1}$

\section{Antimicrobial Resistance (AMR)}

Antimicrobial resistance (AMR) is one of the biggest global public health challenges that currently affects humans, animals, and environmental health. ${ }^{2,3}$ Although it is a natural evolutionary phenomenon, AMR's emergence and spread continue to pose serious threats by the overuse and misuse of antibiotics in humans and animals. ${ }^{4}$ AMR impacts financial sustainability, global health, food sustainability and security, environmental wellbeing, and socio-economic development. ${ }^{5,6}$ AMR has led to adverse consequences, including severe illnesses, more prolonged hospital admissions, increased healthcare costs, an overburdened public health system, higher costs in second-line-drugs, treatment failures, and even increased mortality rates. ${ }^{5-7}$ In recent decades, the development of new antibiotics has
Correspondence: Mainul Haque

The Unit of Pharmacology, Faculty of Medicine and Defence Health, Universiti Pertahanan, Nasional Malaysia (National Defence University of Malaysia), Kem Perdana Sungai Besi, Kuala Lumpur, 57000, Malaysia

Tel +60 109265543

Email runurono@gmail.com 
declined sharply. ${ }^{8,9}$ Moreover, existing antibiotics lose effectiveness due to AMR. ${ }^{1,4-7,10}$ World Health Organization's (WHO) recent report (Global Antimicrobial Resistance and Use Surveillance System (GLASS) Report: Early implementation 2020) published some alarming AMR rates from 78 countries (Box 1). ${ }^{11}$

\section{AMR: Clinical and Financial Burden}

AMR is responsible for the substantial clinical and financial burdens on the health care system, patients, and their families. ${ }^{12-15}$ Every year at least 700,000 people succumb to AMR. If this uncontrolled pattern continues, a cumulative cost of US $\$ 100$ trillion will develop by 2050 ,

\section{Box I Glass Report - Highlights of Reported Resistance}

I. High rates of AMR observed against common bacterial infections

2. Median frequency of resistance in pathogens isolated from patients with bloodstream infections

i. Methicillin-resistant S. aureus (MRSA): I2.I I\% (IQR 6.4-26.4)

ii. E. coli resistant to third-generation cephalosporins: $36.0 \%$ (IQR 15.2-63.0)

iii. K. pneumoniae resistant to third-generation cephalosporins $57.6 \%$ (IQR 33.4-77.8), with 12 countries reporting $80-100 \%$ resistance

iv. Acinetobacter spp.: aminoglycosides 4I.2\% (IQR 5.20-83.3I); carbapenems 63.2\% (IQR 19.78-8I.63)

3. Median resistance to ciprofloxacin in urinary tract infections i. $43.29 \%$ (IQR 23.8-46.4) for E. coli in 33 reporting countries, territories and areas

ii. 38. I\% (IQR 8.4I-63.53) for K. pneumoniae in 34 reporting countries, territories and areas

Note: Data from World Health Organization. ${ }^{\prime \prime}$ undermining the economy which will be comparable with the 2008 financial crisis. ${ }^{14}$ AMR also threatens many sustainable development goals (SDGs). ${ }^{14,15}$ Annually 33,000 people will die in the European Union and European Economic Area (EU/EEA) due to an infection with a resistant bacterial strain by $2050 .{ }^{16}$ The hospital stays for patients with AMR averages around 13 days, causing an additional 8 million hospital days annually, costing up to US $\$ 29,000$ per patient. ${ }^{17,18}$ Table 1 shows the effects of antimicrobial resistance in health care systems by highlighting the estimated cases in hospitalized patients, deaths, and attributable healthcare costs in the USA. ${ }^{19}$

\section{Multidrug Resistance (MDR)}

The AMR situation became further aggravated by multidrug resistance (MDR), one of the most significant clinical practice challenges. $^{20,21}$ Globally about 500,000 new cases of multi-drug-resistant tuberculosis (MDR-TB) are diagnosed yearly. ${ }^{22}$ In $2018,87 \%$ of new TB cases occurred in 30 countries in Asia, Africa, and Latin America. ${ }^{21}$ The highest rates of drug-resistant tuberculosis (TB) have been reported from the European region, with an estimate of 77,000 people ill with MDR-TB/year and 966 cases of extensively drug-resistant TB (XDR-TB), ie, $23 \%$ of the global MDR-TB burden. ${ }^{23}$ Most of the ESKAPE pathogens (Enterococcus faecium, Staphylococcus aureus, Klebsiella pneumoniae, Acinetobacter baumannii, Pseudomonas aeruginosa, and Enterobacter species), the leading causes of life-threatening nosocomial infections amongst critically ill and immunocompromised

Table I Impact of Antimicrobial Resistance in Health Care Systems

\begin{tabular}{|c|c|c|c|c|}
\hline Organisms & $\begin{array}{l}\text { Threat } \\
\text { Level }\end{array}$ & $\begin{array}{l}\text { Estimated Cases in } \\
\text { Hospitalized Patients } \\
(2017)\end{array}$ & $\begin{array}{l}\text { Estimated } \\
\text { Deaths } \\
(2017)\end{array}$ & $\begin{array}{l}\text { Estimated Attributable } \\
\text { Healthcare Costs (2017) US }\end{array}$ \\
\hline Carbapenem-resistant Acinetobacter & Urgent & 8,500 & 700 & $\$ 28 I M$ \\
\hline Clostridioides difficile & Urgent & 223,900 & 12,800 & $\$ I B$ \\
\hline Carbapenem-Resistant Enterobacteriaceae & Urgent & 13,100 & 1,100 & $\$ 130 M$ \\
\hline Drug-Resistant Neisseria gonorrhoeae & Urgent & 550,000 & $1.14 \mathrm{M}$ & $\$ 133.4 \mathrm{M}$ \\
\hline Vancomycin-Resistant Enterococci (VRE) & Serious & 54,500 & 5,400 & $\$ 539 M$ \\
\hline $\begin{array}{l}\text { Multidrug-Resistant Pseudomonas } \\
\text { aeruginosa }\end{array}$ & Serious & 32,600 & 2,700 & $\$ 767 M$ \\
\hline Methicillin-Resistant Staphylococcus aureus & Serious & 323,700 & 10,600 & $\$ 1.7 \mathrm{~B}$ \\
\hline $\begin{array}{l}\text { Extended-Spectrum Beta-Lactamase } \\
\text { (ESBL) Producing Enterobacteriaceae }\end{array}$ & Serious & 197,400 & 9,100 & $\$ 1.2 \mathrm{~B}$ \\
\hline Drug-Resistant Tuberculosis (Tb) & Serious & 847 & 62 & $\begin{array}{l}\$ 164,000 \text { Per MDR case } \\
\$ 526,000 \text { Per XDR case }\end{array}$ \\
\hline
\end{tabular}

Note: Data from Centers for Disease Control and Prevention. ${ }^{19}$ 
individuals are multidrug-resistant isolates and these pose most significant challenges in clinical practice. ${ }^{20}$

\section{COVID-19: Extra Burden on AMR}

The Coronavirus disease, COVID-19, is a new threat to global public health. Many COVID-19 patients with mild disease without pneumonia or moderate disease with pneumonia take antibiotics (eg, azithromycin), which are not recommended by health authorities. ${ }^{24}$ WHO has already warned that "increased use of antibiotics to combat the COVID-19 pandemic will strengthen bacterial resistance and will lead to more deaths during the crisis and beyond". 25 The pandemic may threaten antimicrobial stewardship (AMS) activities and increase AMR. ${ }^{25,26}$ While reviewing antimicrobial prescribing in COVID-19 patients, it was found that $72 \%$ of 2,010 COVID-19 patients received broad-spectrum antimicrobial therapy in the hospitals, although only $8 \%$ suffered bacterial and fungal co-infection. ${ }^{27}$ This antimicrobial prescribing pattern could increase the long-term threat of AMR. ${ }^{27,28}$ WHO has discouraged the "inappropriate use of antibiotics, particularly among patients with mild COVID-19 symptoms". 29 Furthermore, increased antimicrobial use may occur due to increased hospital admissions during the COVID-19 period, which in turn may pose the risk of health-care-associated and multidrug-resistant infections. $^{30}$

\section{The Paucity of New Antibiotics! A Need for Urgent Action}

Experts have declared that we are close to the age of no effective antibiotics as the crest of the AMR challenge appears. ${ }^{31,32}$ Since the late 1990 s, the discovery and development of new antibiotics have slowed dramatically, where only three new antibiotics received FDA approval in the last 30 years. ${ }^{8,9}$ Two recent WHO reports on clinical and preclinical drug development highlighted a weak pipeline for antibiotic agents, which may threaten global efforts to contain drug-resistant infections. ${ }^{33,34}$ The majority of 50 antibiotics in clinical studies in the drug development pipeline have limited benefits, and 252 products in the preclinical phase of the drug development are in the very early stages of testing and might be available in about ten years. ${ }^{33-35}$ Due to the drought of new antibiotics and the withdrawal of some major pharmaceutical companies from the field of antimicrobials, WHO recently issued a fresh warning regarding the global threat of AMR. ${ }^{34}$ To exacerbate the AMR threat, major pharmaceutical companies involved in AMR research have left the market due to a "lack of incentives" and dwindling funding. ${ }^{36}$ Two recent WHO reports confirmed that clinical and preclinical drug development is predominantly driven by the small- or medium-sized enterprises (SMEs), as large pharmaceutical companies continue to leave the business. ${ }^{33,34}$ Furthermore, the level of research and development (R\&D) investment in clinical development is insufficient to meet global health needs, in contrast to the more robust and vibrant preclinical biotechnology pipeline. ${ }^{37}$ Hence, there is a paucity of new drugs in the research and development pipeline of the pharmaceutical industry.

\section{Aim of the Review}

Against this background, it is important that appropriate antimicrobial prescribing and stewardship strategies evolve to support rational treatment and prevent AMR's unintended consequences. This review highlights AMR's scale and consequences, the importance and implications of the ASP, to fight resistance and protect global health.

\section{Literature Search}

Relevant literature was searched using PubMed, Scopus, and Google Scholar using specific keywords, eg "Antimicrobial resistance," "Multidrug-resistant," "Antimicrobial Stewardship Program," "Monitoring and evaluation," "One Health," and "Global Health." Original studies, reviews, editorials, commentaries, perspectives, short or unique communications, and policy papers on antibiotic resistance and antimicrobial stewardship were reviewed. Information from Websites of different professional associations and international or national organizations were searched to extract relevant information.

\section{AMS - Definition}

Antimicrobial stewardship (AMS) is defined as "an organizational or healthcare-system-wide approach for fostering and monitoring judicious use of antimicrobials to preserve their effectiveness". 38 The concept of AMS was promulgated by the Infectious Diseases Society of America (IDSA) in 2007. It was originally defined as organized interpositions with the premise of improving antimicrobial use when selecting the appropriate agents, the correct dose, route of administration, and the duration of therapy without prejudicing patient outcomes. ${ }^{39,40}$ AMS refers to a set of coordinated strategies to (i) improve patient care, and outcomes by optimal therapy; (ii) reduce 
collateral damage by reducing antimicrobial use (less resistance), and (iii) reduce the cost for antibiotics. ${ }^{41}$ These strategies can be used globally to help control AMR by increasing awareness of the public and educating healthcare professionals on the prudent use of antimicrobials as part of an ASP. Overall, AMR should be considered a global priority, and all countries and organizations should make coordinated efforts to implement new policies and research concerning ASP.

\section{History of AMS}

In the 1940s, Sir Alexander Fleming warned about antibiotic resistance, and his prediction became true within ten years due to the misuse of the drugs. ${ }^{42}$ Since then, educational programs, quality management protocols, and clinical guidelines were developed by infectious-disease professional organizations to prevent and control the problem however, these were found mostly ineffective. ${ }^{42}$ In a 1996 article, McGowan and Gerding pioneered the term "antimicrobial stewardship," emphasizing that the process should be considered an integral "part of every antimicrobial treatment decision". ${ }^{43}$ They included the term "Antimicrobial Stewardship" in the antibiotic resistance prevention guidelines published in 1997 by the Society for Healthcare Epidemiology of America (SHEA) and IDSA. ${ }^{44}$ In 2007, IDSA and SHEA formally adopted the term in a "programmatic activity" ${ }^{45}$ Later, the term was assumed by the two European scientists in 1999, Ian Gould and Jos van der Meer, who helped to disseminate it through their organization called the European Society of Clinical Microbiology and Infectious Diseases Study Group for Antimicrobial Stewardship. This helped to popularize the term worldwide. ${ }^{46}$

In the USA, CDC launched the first educational program in 2009 to advocate the rational use of antibiotics in acute-care settings and adopted improved antibiotic use as a strategy in 2013 to tackle the problem. ${ }^{47,48}$ Various accrediting agencies have highlighted the need for and importance of antibiotic stewardship programs (ASPs) in clinical practice settings. ${ }^{49}$ A study conducted in 2014 showed that only $39 \%$ of clinical practices had used antimicrobial stewardship programs. ${ }^{50}$ In 2017, the government urged that all hospitals must have stewardship programs in their organizational mandates. ${ }^{51}$ In Europe, many countries implemented cost-effective antibiotic stewardship programs nationally or regionally to raise awareness about adequate antibiotic use, facilitate monitoring and surveillance, and provide feedback on prescribing behavior; and implement cost-effective approaches. $^{52}$ In 2017, the European Commission issued guidelines on the prudent use of antimicrobials in humans ${ }^{53}$ and published a report highlighting the countries' progress in $\mathrm{AMS}^{54}$ WHO (Europe Region) has published a review of public awareness campaigns in relation to $\mathrm{AMS}^{55}$

Though AMS programs have proven to improve antibiotic use in developed countries, AMS strategies to contain AMR are unsuccessfully executed in developing countries $^{56}$ which has led to an urgency to establish, implement and evaluate effective AMS programs ${ }^{57-59}$ in these territories. To tackle this emergency, in 2016, the WHO and the United Nations General Assembly ratified the implementation of AMS programs globally and at the institutional-level. ${ }^{60-62}$ Recently, WHO published an AMS toolkit for developing countries and highlighted the importance of local context in developing and implementing AMS programs. ${ }^{63}$

\section{AMS - An Integral Component of Health Systems}

AMS is a collaborative, multifaceted, and multidisciplinary approach that engages healthcare leaders, microbiologists, infectious disease specialists, physicians, nurses, farmers, veterinarians, IT experts, and clinical pharmacists to improve patient treatment outcomes and safety by reducing AMR development. ${ }^{64,65}$ With the growing reciprocity between human and animal health, "veterinary antimicrobial stewardship" focuses on animal health (livestock and companion animals). ${ }^{46}$ The "One Health" concept birthed through a multidimensional organizational approach resulting in the provision of policies, guidance documents, improved surveillance, prevalence and incidence reports, education, and audit of practice internal and external to the healthcare institution. ${ }^{46,66,67}$

One of the three tenets of an integrated approach to health systems strengthening is AMS. The other two are infection prevention and control (IPC) and medicine, followed by patient safety. ASP's success is Infection Control Programs' (IPC) inclusivity as the individual aspects of an IPC cannot be performed independently. ${ }^{68,69}$ Infection preventionists and healthcare epidemiologists are critical in ASP's deployment and success. ${ }^{70}$ The optimization of antimicrobial usage assists AMS to control AMR when associated with antimicrobial use, surveillance, and the WHO essential medicines list (EML) AWaRe16 
classification (ACCESS, WATCH, RESERVE). In combination with AMR surveillance and the adequate supply of quality-assured medicines, these three pillars promote equitable and quality health care towards the goal of achieving universal health coverage. ${ }^{63}$

These areas are intrinsically linked to the issues associated with antimicrobial agents' use, the proliferation and spread of AMR, education, and require filiation and structure across the various coincident disciplines and clinical settings. ${ }^{69}$ This multipronged approach means with no transmission of infection, the need for antimicrobial treatment is eliminated, therefore decreasing resistance development. ${ }^{71}$ In 2019, the CDC developed seven (7) fundamentals for ASP implementation (Box 2). ${ }^{71}$ Notably, leadership and accountability are the first two principles, responsible for the program's deliverables and outcomes, followed by education and local antibiogram implementation. The administrative component includes education and the institution of local antibiograms, which hinges upon the principle that the appropriate empiric therapy is administered for common infections. $^{71}$ Actionable items such as the preauthorization of prescriptions and resistance surveillance are performed by pharmacists and laboratorians, respectively, where the requisite interventions can occur as dictated by institutional guidelines and policies. ${ }^{72}$

\section{AMS - Importance for Patient and Public Health}

With AMR being a well-documented phenomenon that portends public health stability and national security, it has been recognized as a global threat by WHO. ${ }^{73}$ Public health

\section{Box 2 Core Elements of the Antibiotic Stewardship Program}

- Leadership commitment towards necessary human, financial, and information technology resources.

- Accountability through a single physician/pharmacist leader for program management and outcomes.

- Drug expertise through an only pharmacy leader to help lead implementation efforts to improve antibiotic use.

- Action to implement interventions, such as prospective audit and feedback or preauthorization, to improve antibiotic use.

- Tracking prescription, the impact of interventions, resistance patterns, and other important outcomes.

- Reporting prescription and resistance information directly to prescribers, pharmacists, nurses, and hospital leadership.

- Education for health care professionals (prescribers, pharmacists, nurses) and patients about adverse reactions from antibiotics, antibiotic resistance, and optimal prescribing.

Note: Data from Centers for Disease Control and Prevention. ${ }^{71}$ organizations' affiliation with healthcare providers (HCPs) is crucial. It facilitates the creation of prevention strategies, the promotion of education, and surveillance, all in an effort to limit the advancement of AMR. ${ }^{74}$ Daily, physicians are confronted by patients who are unresponsive to currently available antimicrobials, forcing them to use reserved antibiotics such as carbapenems and polymyxins, which are expensive and may not be readily available in some countries and can have potentially unintended consequences (eg, colistin and acute kidney injury). ${ }^{7,75,76}$ Clinicians are dealing with a global challenge of Multi-Drug Resistant Organisms (MDROs) in the ESKAPE pathogens, notoriously branded as "bugs without borders"20,67,77,78 and are nosocomial pathogens capable of "escaping" the biocidal action of antimicrobial agents. ${ }^{78,79}$ The urgency of addressing AMR is well recognized through the innocuous and operative healthcare delivery via ASP. ${ }^{7,75}$ Since its inception, ASP has proven highly successful in improving antibiotic use. Notably, the 4 Ds of optimal antimicrobial therapy are; right Drug, right Dose, De-escalation to pathogen-directed therapy, and right Duration of therapy and infection control. These are the guiding principles of ASP. ${ }^{79,80}$ These strategies are closely aligned to the public health objectives and are not limited to promoting AMS strategies, monitoring, transparency of data, infrastructure building, and increased knowledge and awareness at the patient and HCP levels (Box 3). ${ }^{74,81,82}$

The lack of antibiotic development requires the conservation of existing ones. IDSA and other organizations support the institution of capable ASP geared towards preserving the use of effective drugs through improved resistance and infection surveillance, data collection, infection prevention, and other control measures to ensure the judicious use of new antibiotics. ${ }^{83}$ Furthermore, to reduce selective pressures that favor highly resistant pathogens, a set of structured antimicrobial steward programs have been globally implemented in medical settings. ${ }^{84}$

Successful implementation has seen annual cost savings of stewardship programs at US $\$ 200 \quad 000-\$ 900$ $000 .{ }^{85-87}$ One glaring example is from the University of Maryland, the USA, where over 3-years, a stewardship program reduced approximately US $\$ 3$ million in antibiotic expenditures. When the program was discontinued, an immediate increase in approximately US \$2 million antibiotic expenditure was observed over the next two years. ${ }^{85}$ In Barbados, the antimicrobials used to treat patients during a Klebsiella pneumoniae carbapenemase (KPC) outbreak in 2012 accounted for 64\% of hospital costs 
Box 3 Antimicrobial Stewardship Aligns with the 10 Essential Services of Public Health

- Antimicrobial susceptibility patterns and antimicrobial utilization trends monitor and detect at the national, state, regional, and community levels.

- Surveillance of antimicrobial susceptibility across nations, states, regions, and communities.

- The provision of information through education empowers patients, healthcare providers, and other agencies on appropriate antimicrobial use.

- Collaborate with the community's organization, such as non-governmental and governmental organizations geared towards patient safety regionally and nationally, hospitals, long-term care facilities, and healthcare systems in promoting antimicrobial stewardship strategies across regions, particularly with shared patient populations.

- Identify and share best practices and policies in AMS widely.

- Provide advocacy initiatives for promoting legislation to improve patient safety, reduce exposure, and develop resistant infections.

- Establish linkages amongst healthcare entities to enhance AMS across regions.

- Ensure effective ASP is established within healthcare facilities.

- Monitor and evaluate ASP towards improvement in healthcare facilities.

- The creation of innovative research solutions to obstacles in AMS implementation.

Note: Data from these studies. ${ }^{74,81,82}$

associated with those antibiotics. ${ }^{88}$ There was a $60 \%$ decline in carbapenems and vancomycin. ${ }^{63,88}$

Notably, most studies on AMS focus on pharmacy costs for antibiotics. Other savings can be garnered with a reduction in lengths of stay and readmission rate, making it even more significant. ${ }^{64}$ Importantly, disability-adjusted life years (DALYs) caused by five reported infections associated with antibiotic-resistant bacteria across various populations in Europe was substantial compared to other infectious diseases inclusive of all the associated factors. ${ }^{89,90}$ Although these cost-benefits are actualized readily amongst infectious disease specialists, if the benefits are truly seen, they must be embraced by patient groups and non-infectious disease specialists as they fit within the context of improving patient safety and reducing health related costs associated with AMR.

Antibiotic resistance impacts the immune system's capacity to fight infectious diseases. It introduces complexity in managing patients undergoing chemotherapy, transplantation, and other care areas reliant on effective antimicrobial therapy since antibiotics cause dysbiosis or disruption in the commonly "diverse" intestinal flora or gut microbiome. ${ }^{7,75,91,92}$ Similarly, the management of comorbid conditions like diabetes, asthma, and rheumatoid arthritis are significantly impaired by antibiotic resistance. ${ }^{91}$

To monitor, evaluate, and inform further action on AMR's dispersal, surveillance is essential at the local, national, and global levels and assesses the strategies employed. ${ }^{93,94}$ The WHO launched GLASS in October 2015 to "strengthen knowledge through surveillance and research"93 and provides a homogenous approach to AMR data collection, analysis, and dissemination by country, seeking to register the authenticity of existing or newly developed national AMR surveillance systems. ${ }^{93,94}$ It promotes a system that includes epidemiological, clinical, and population-level data compared to reliance on laboratory data only. ${ }^{93,94}$

GLASS promotes integration with other surveillance programs in public health, the animal and environment sectors, facilitating the surveillance of resistance in eight priority bacterial human pathogens, some with links to the food chain, and monitors antimicrobial consumption by humans. ${ }^{93,94}$ The Tripartite Collaboration with the UN Food and Agriculture Organization (FAO), the World Organization for Animal Health (OIE) and GLASS provides a comprehensive understanding of AMR across the multiple sectors to promote the One Health Approach AMR control. ${ }^{93,94}$ A calculation of the extent of AMS integration within the whole health economy is critical in understanding how a "One Health" approach is incorporated in combatting AMR. ${ }^{95}$ The concentration of AMS activity has been primarily hospital-based, which may be practical but artefactual. It fails to address the bidirectional flow between hospital and community care services as antimicrobial use in the community is associated with AMR development in and outside hospitals. ${ }^{95,96}$

The One Health perspective on integration involves multiple sectors communicating and working together to design and implement programs, policies, legislation, and research to achieve better public health outcomes. However, the approach must be influential and supervisory in nature for public engagement. ${ }^{95,97}$ However, AMS's medical strategies cannot be adopted wholesale to veterinary medicine due to disparaging factors not limited to the lack of fund and expertise, topographical reach, political commitment, and nominal mechanization supporting the AMS veterinary sector. ${ }^{98}$ With this in mind, strategies for AMS which are innovative and appropriate to the size, inclusive and resourceful will be required. Behavioral 
change is an important factor in the program's sustainability and has proven effective in improving antimicrobial prescribing. ${ }^{98-100}$ To add further complexity, increases in local temperature have been implicated in higher antibiotic resistance levels in Escherichia coli, Klebsiella pneumoniae, and Staphylococcus aureus. Hence, climate change and population increases will contribute to AMR, giving credence to ASP's need. ${ }^{101}$ Public health organizations are poised to promote AMS across all health care disciplines and institutions, ideally for the preservation of antimicrobials for future use, reduction in collateral damage, decreased morbidity and mortality, and a reduction in antibiotic selection pressures. ${ }^{74}$

\section{Principles and Practice of AMS}

The right antibiotic, for the right indication (right diagnosis), the right patient, at the right time, with the right dose, route and duration of therapy, causing the least harm to the patient and future patients. (www/cdc.gov/get smart/healthcare/inpatientstewardship). ${ }^{102}$ This definition outlines the fundamental principles of antibiotic prescribing. If implemented strictly, these principles ensure that healthcare professionals only prescribe antibiotics for non-self-limiting bacterial infections. ${ }^{103}$ Formulary policies, such as monotherapy used instead of combination therapy, which covers the likeliest etiological agent or pathogenic organism relevant to the site of infection, should be employed whenever possible. ${ }^{104}$ Combined therapeutic agents consisting of two or more drugs together from different classes lead to synergism, particularly against resistant Gram-negative bacteria. Narrow-spectrum antibiotics should be chosen with low resistance potential. ${ }^{105,106}$ "Antibiotic adjuvants are nonantibiotic compounds that increase antibiotic activity either by blocking resistance or by boosting the host response to infection" "107 Antibiotic adjuvants are also known as antibiotic resistance breakers (ARBs). ${ }^{108}$ Currently, multiple studies reported that novel antibiotic adjuvants strategy opens new window as a substitute, equilateral, and supportive path to combat AMR. Quite a few ARBs are now in clinical use. For example, compounds that hinder the $\beta$-lactamases that converse resistance to $\beta$-lactam antimicrobials. Furthermore, these new molecules improve efficacy (re-sensitizing resistant pathogens to antimicrobials) ${ }^{108}$ of frequently used antimicrobials against MDR Gram-negative microbes by overcoming resistance and virulence of these pathogens. ${ }^{107,109-112}$ Three different categories of antibiotic adjuvants currently available include: (a) $\beta$-lactamase inhibitors; (b) efflux pump inhibitors; and (c) outer membrane permeabilizer. ${ }^{11,113}$
Limiting the number of accessible antimicrobials through a selectively restricted formulary is the optimal way to regulate resistance. Restrictions are applied only to high resistance-potential antibiotics, for example, imipenem (not meropenem or ertapenem), ceftazidime (not other third or fourth generation cephalosporin), and gentamicin/tobramycin (not amikacin). ${ }^{114}$ Antimicrobial cycling employs antimicrobial rotation to reduce the selection pressure on a particular drug with scheduled substitutions of a class (or a specific member of a class) and a different class (or a specific member of a class) that exhibits a comparable spectrum of activity (Box 4).

Front-end restriction requires preauthorizing certain antimicrobials by a member from the AMS team or based on a set of pre-authorized criteria determined by a pharmacist. Back-end restrictions refer to the review and intervention after the antimicrobial is prescribed by an AMS member who reviews current antimicrobial regimens. Prescribers are provided with the recommendation of continuation, adjustment, discontinuation, or modification of the therapy based on the clinical and microbiological features of the case. ${ }^{72,115}$ Both methods require prospective auditing, intervention, and feedback. $^{72}$

Minimizing collateral damage, eg, C. difficile diarrhea/ colitis and preferentially select antibiotics with low resistance to $C$. difficile, MRSA, ESBL, Metallo $\beta$-lactamase (MBL) strains, VRE, and Carbapenem-Resistant Enterobacteriaceae (CRE). ${ }^{116-118}$ Switch from IV-to-oral antibiotic therapy after clinical defervescence and using oral antibiotics initially, if tolerable to the patient. ${ }^{119-122}$ Therapeutic substitutions in consideration with the facility's antibiogram are employed, and a single antimicrobial per class is maintained to reduce pharmacoeconomic cost and inventory. ${ }^{123}$ Implications of cost to the institution regarding dosing frequency, $C$. difficile development,

\section{Box 4 Types of Stewardship Interventions}

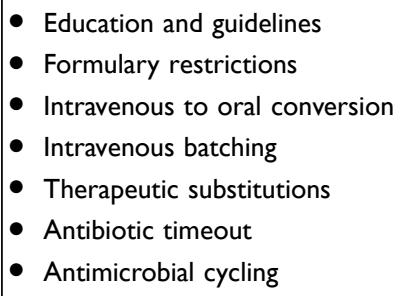

Note: Copyright (C) 2020. Pharmacy Times. Reproduced from Pharmacy Times. Antimicrobial Stewardship: A Primer for Hospital Pharmacists. Available from: https://www.pharmacytimes.com/publications/health-system-edition/2016/ march20I6/antimicrobial-stewardship-a-primer-for-hospital-pharmacists. 
resistance potential, the measure of activity against the likely agent, and the cost of potential therapeutic failure given increased length of stay and legal implications must be considered. ${ }^{124,125}$ Intravenous batching is also a consideration where single-use vials can be batched using written protocols to reduce costs and waste. ${ }^{72}$ This intervention is the "timeout" of antibiotics after 72 hours of initiation. An interruption during interdisciplinary rounds to assess the indicated antimicrobial appropriateness, verify current culture and sensitivity results, followed by therapy de-escalation if indicated, is performed. ${ }^{71,126}$ This ensures proper use, dosing, and duration of each antimicrobial agent and allows scrutiny by the AMS team. $^{72}$

De-escalation and streamlining refer to prescribing antimicrobials based on the laboratory findings of culture and sensitivity. Thereby substituting to more selective therapeutic options from broad-spectrum antimicrobials. Additionally, the administration route needs to be altered, such as the intravenous to the oral route, or suspending antimicrobials if the infection is adequately controlled or not detected with advanced laboratory technology. ${ }^{39}$ Other strategies include promotion of timely and appropriate microbiology sampling, ${ }^{127,128}$ prospective audit with intervention and feedback, ${ }^{39,74,129}$ surgical antibiotic prophylaxis optimization, ${ }^{130,131}$ and therapeutic drug monitoring with feedback. ${ }^{132,133}$

\section{AMS - A Shared Responsibility}

The multidisciplinary team comprising microbiologists, infectious disease physicians, clinical pharmacists, nurses, laboratorians, and the infection control specialists make antimicrobial stewardship attainable. They are the program's backbone and provide feedback on prescribing practices, antimicrobial usage, medication safety incidents, local AMR patterns, antimicrobial resistance-related or complicated infections, and changes in national policies and guidelines, new therapeutic options, and innovative diagnostic interventions. ${ }^{134-137}$ With the "One Health" approach, an even more comprehensive set of stakeholders are involved, including agriculturalists, veterinarians, economists, farmers, etc. ${ }^{67}$ Nurses have an important role in antibiotic preparation, administration, prescription, and therapeutic monitoring. ${ }^{138,139}$ A single leader (usually an ID specialist) should be appointed for accountability, drug expertise and program oversight. The pharmacist leader should be responsible for optimizing antibiotic use. This leadership commits to supporting a dedicated team of persons and providing budgetary and information technology resources. Figure 1 shows the stewardship team's fundamental approaches which are needed to overcome the AMR. ${ }^{69}$

Through the advent of rapid diagnostics such a molecular diagnostics and mass spectrometry, the prolonged use of broad-spectrum antibiotics is reduced, allowing earlier de-escalation, changing from combination to monotherapy where necessary or stopping antibiotic therapy entirely, ${ }^{79,140,141}$ and facilitates the earlier optimized treatment regimen. ${ }^{142-144}$ With cascading microbiology susceptibility reporting, the microbiology laboratory reports broad-spectrum drugs only if the primary drugs are resistant and only the narrowest-spectrum drugs (primary agents) are reported while withholding the susceptibilities of more broad-spectrum agents, higher-cost agents, hightoxicity agents, or those with the potential for over-prescription (secondary agents). The rationale behind cascade reporting is that they will be less likely to be prescribed. ${ }^{145}$ The reduction of broad-spectrum antibiotics and a concerted effort to promote narrow-spectrum therapies will provide heterogeneity in prescribing instead of homogeneity, which increases resistance to heightened selective pressures. ${ }^{114}$ In the form of empiric antibiotic recommendations for common infections, dosing guidelines, and other helpful information, treatment algorithms are devised, prompting the prescriber to make evidencebased decisions founded on antibiograms and national surveillance data. ${ }^{146,147}$

Dose optimization using pharmacokinetic/pharmacodynamic properties to improve drug efficacy based on the organism, infection site, and patient characteristics has also demonstrated clinical effectiveness. ${ }^{148,149}$ Formulary restrictions, automatic substitution/therapeutic interchange policies, and preauthorization have been applied to control the misuse of antimicrobials by establishing order forms, consultation with infectious disease experts, and clinical pharmacists on the use of the high-cost broad-spectrum drugs. $^{39,150,151}$ These methods facilitate appropriate and timely antimicrobial administration in severe sepsis/septic shock, where urgent intervention is critical for patient survival. $^{152,153}$ The World Organization for Animal Health has listed and categorized antimicrobials not to be used in animals, plants, or aquaculture, particularly carbapenems, glycopeptides, oxazolidinones, and any new classes of antimicrobials developed for humans. ${ }^{67,154}$ Clinical education regarding antimicrobial stewardship at all medical and health professional schools has prompted 


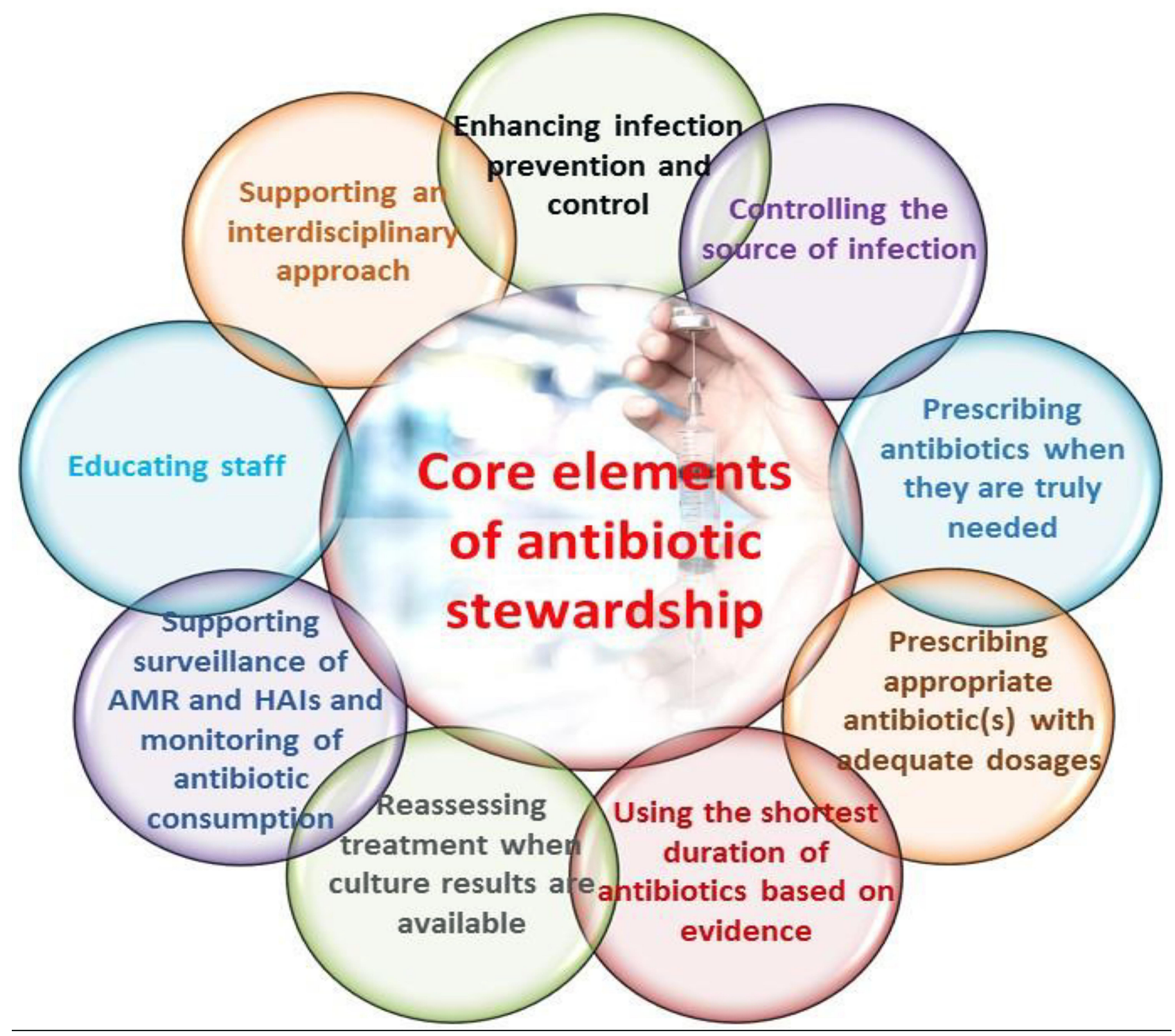

Figure I Core elements of ASP to optimize the treatment of infections and reduce adverse events associated with antibiotic use.

Notes: Copyright (C) 2020. Global Alliance for Infections in Surgery. Reproduced from Global Alliance for Infections in Surgery. Core elements of antibiotic stewardship. Available from: https://infectionsinsurgery.org/core-elements-of-antibiotic-stewardship/. ${ }^{69}$

the development of prescribing policies and competencies, antibiograms, infection control, and hand hygiene practices. ${ }^{19,125}$ The continuity of care is maintained through multidisciplinary meetings engaging the various departments to discuss prescribing patterns, local antibiograms, and to address their concerns regarding de-escalation and appropriate antimicrobials utilization. Public education and awareness campaigns about mitigating AMR have been established. ${ }^{135}$

The CDC's seven core elements to establish a successful ASP at the institutional level (Box 2) exemplifies the integrative approach towards $\mathrm{AMS}^{71} \mathrm{AMS}$ is a shared responsibility among primary prescribers, pharmacists, ID physicians, nurses, veterinarians, farmers, and microbiologists to provide appropriate antimicrobials to those who need them, essentially decreasing the acquisition of nosocomial infections and MDROs. Knowledge and awareness are critical components of successful implementation and sustainability to combat AMR. ${ }^{139}$

\section{ASP - Monitoring and Evaluation}

ASPs should be monitored and evaluated using appropriate and relevant outcome indicators. Empirical studies report that AMS programs positively affected the outcome indicators, eg, antibiotic consumption, the intensity of 
consumption, antibiotic prophylaxis, resistance rates, healthcare costs, and morbidity and mortality rates. ${ }^{155,156}$ A number of recent meta-analysis and systematic reviews on ASPs demonstrate the potential to reduce similar outcomes in various healthcare settings. ${ }^{157-161}$ Table 2 highlights the impact of ASPs in some recent studies in developed and developing countries.

\section{AMS - Role of Education and Training}

Education and training on appropriate antimicrobial prescribing and use, AMR, and AMS principles can provide the foundation of knowledge for effective AMS programs. ${ }^{39,170}$ AMS principles should be taught at the undergraduate level and continue throughout professional careers. ${ }^{71,103}$ AMS has been more successful if education began early in the undergraduate curriculum.${ }^{170}$ Studies showed that many undergraduate health professional students do not receive adequate education in relation to AMR, optimal antimicrobial use, and AMS. ${ }^{171-174}$ Health professionals should receive education and training during the infancy of their career, where it helps shape their attitudes and behaviors and better equips them with AMS principles and strategies. ${ }^{175,176}$

AMS education should be available for health professionals as a continuing medical education (CME) program to receive current evidence-based information regarding rational and appropriate prescribing. ${ }^{170}$ Some practical examples of continuing education include lectures, tutorials, in-service and grand rounds sessions, department or practice meetings, morbidity and mortality meetings, academic detailing, one-on-one patient-directed education, elearning, and education combined with other AMS activities. ${ }^{176,177}$ The training programs require continuous monitoring and evaluation to examine the impact of education on students' and professionals' knowledge and behavior.

A recent editorial published in the Bulletin of the World Health Organization emphasized integrating AMS activities into the COVID-19 pandemic response program of the health care system. ${ }^{26}$ The first and important strategy was to increase the health personnel's clinical competence through targeted training. ${ }^{26}$ The key competencies need to implement effective AMS programs are to (i) diagnose signs and symptoms of severe COVID-19 with superimposed bacterial or fungal diseases, (ii) avoid inappropriate antibiotic use including daily de-escalation, (iii) identify the use of medical devices and others that decrease the chances of hospital-associated infections and antibiotic use, and (iv) adopt strict infection prevention and control measures.

\section{The Way Forward: Protecting Global Health Global and National Strategies Against AMR}

A comprehensive response against AMR must be embraced in a holistic manner to contain and mitigate health and the economic consequences associated with AMR. The WHO established The Global Action Plan on AMR after the plan's endorsement at the sixty-eighth World Health Assembly in May 2015. ${ }^{62}$ Subsequently, global leadership has consistently highlighted AMR as a health priority, as illustrated by G7 and G20 countries in summit declarations since $2015 .{ }^{178}$ At the core of the WHO's plan, there are five objectives which include i) improving awareness and understanding of AMR, ii) strengthening knowledge through surveillance and research, ii) reducing the incidence of infection, iv) optimizing the use of antimicrobial agents, and v) developing the economic case for sustainable approaches towards developing new medicines, diagnostic tools, vaccines and other interventions. ${ }^{62}$

While emphasizing the importance of the WHO's Global Action Plan and its endorsement by world leaders; pre-existing national and international strategies against AMR must continue in complete alignment with the global action plan. ${ }^{179-181}$ In 2018 a WHO update stated that 105 countries had surveillance systems in place for reporting drug-resistant infections in human health, 68 countries had systems for monitoring the consumption of antimicrobials, and 123 countries had policies to regulate the sale of antimicrobials, including the requirement of a prescription for human use. ${ }^{182}$

National strategies against AMR must address countryspecific priorities based on social demographic factors. The strategy should also focus on i) strengthening human and animal health surveillance for resistant microorganisms, ii) establishing human and veterinary AMS and infection-control programs, iii) conducting research on innovative diagnostic and therapeutic approaches, and iv) implementing educational programs that target professional groups and the public. ${ }^{183}$ Both global and national 


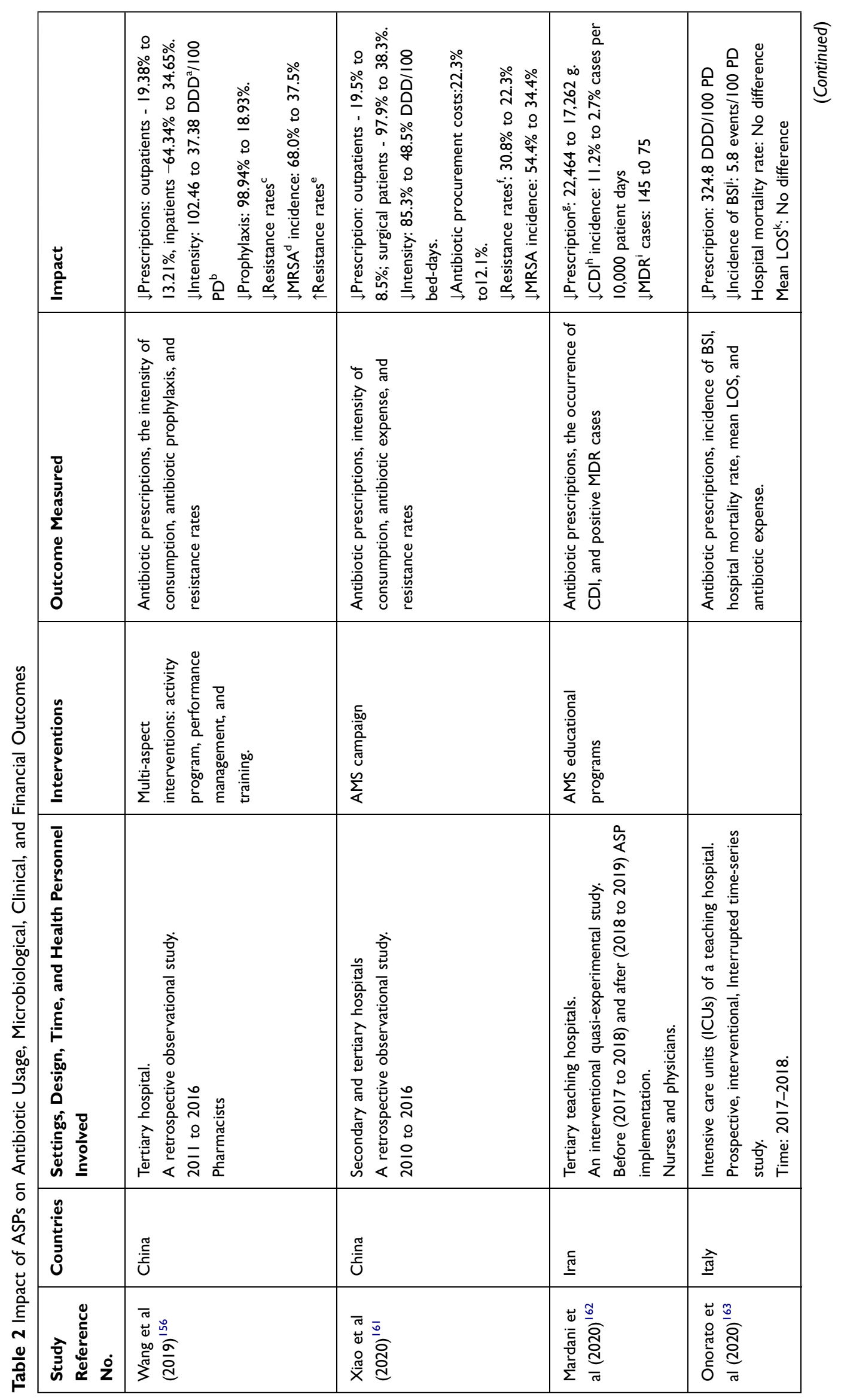




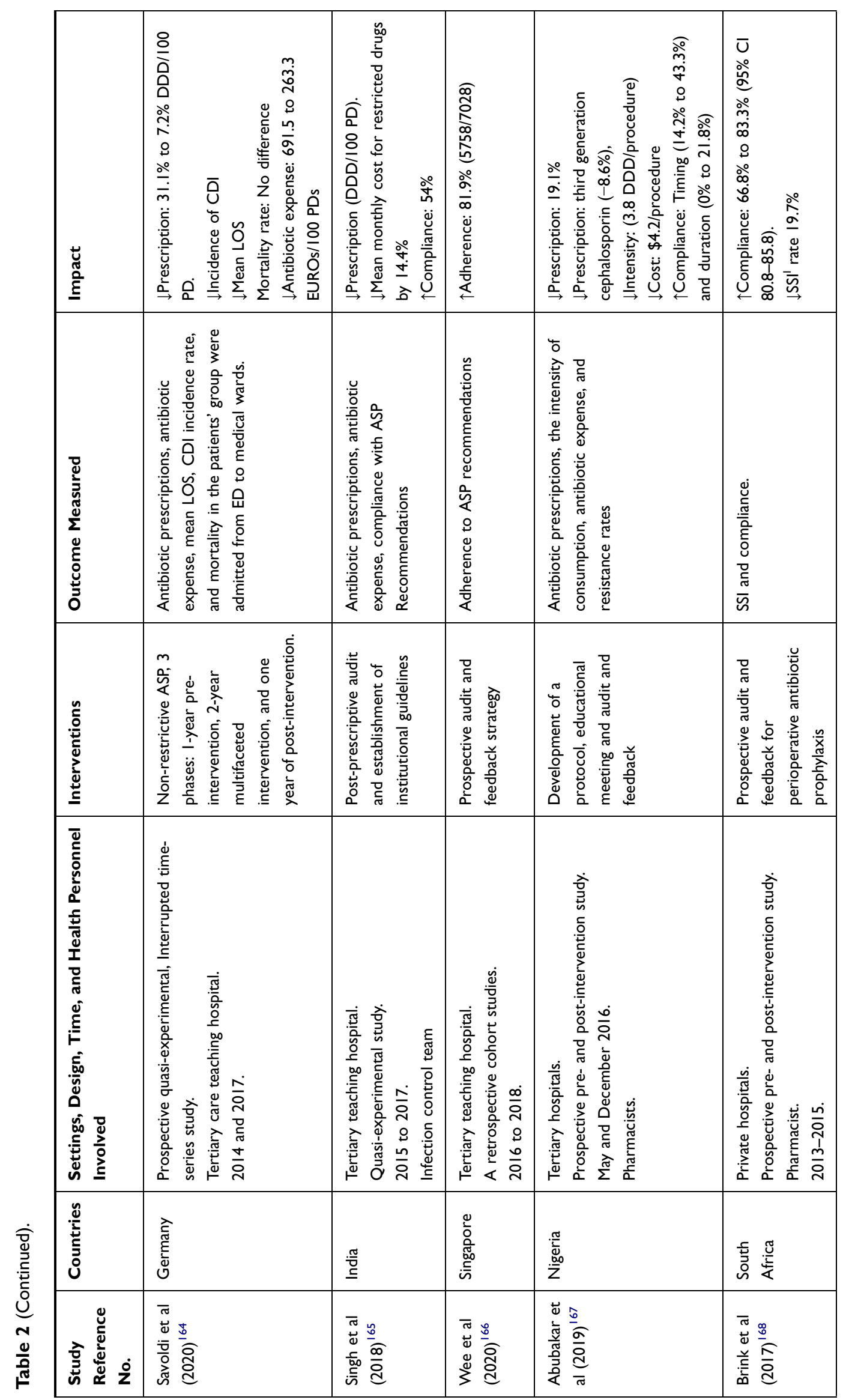




\begin{tabular}{|c|c|}
\hline 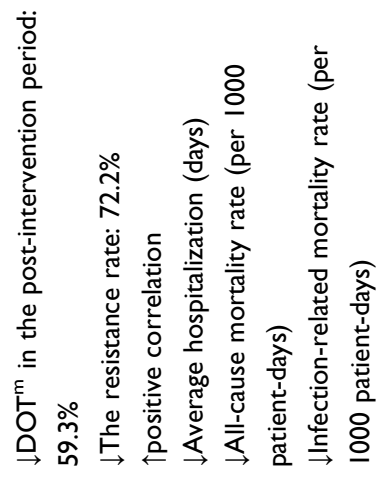 & 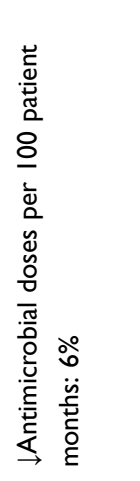 \\
\hline 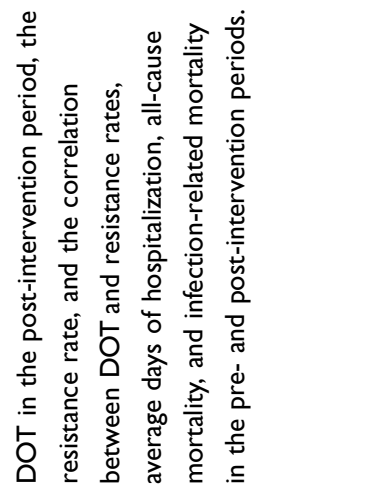 & 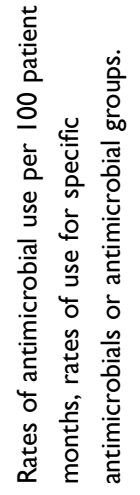 \\
\hline 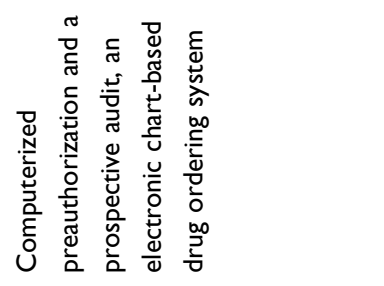 & 产 \\
\hline 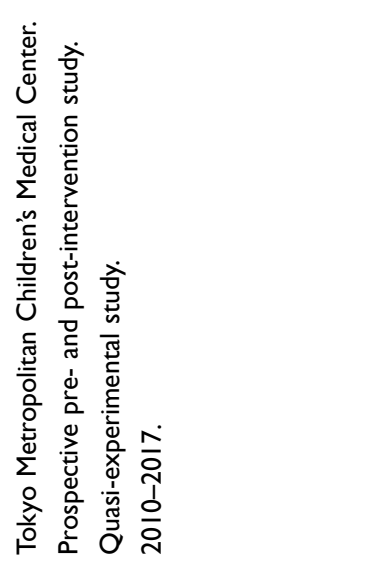 & 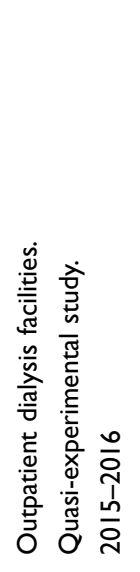 \\
\hline 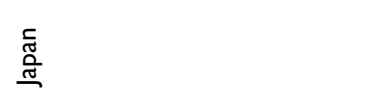 & گ \\
\hline 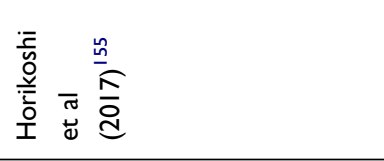 & 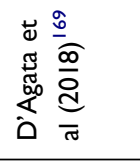 \\
\hline
\end{tabular}

strategies must consider that the occurrence of AMR involves multiple links and domains from production to the use of antimicrobial agents. More so, holistic AMR control requires multiple sectors' joint actions. ${ }^{183,184}$ The WHO "One Health" approach addresses a holistic, multisectoral approach, involving many different sectors (human medicine, veterinary medicine, research, animal husbandry, education, and communication) to increase the AMR action plan. ${ }^{97}$

\section{Action Plans on AMR and ASP}

Embedded in the global and national action plans' objectives should be key aspects of the more clinically guided ASP. The stewardship program contributes significantly to the health care system-wide or organizational approach to promoting and monitoring antimicrobial agents' use to preserve their future use in human and veterinary health. ${ }^{103}$ The following illustrates key initiatives that could be led or influenced strongly by ASP for human and veterinary health. These initiatives require a multipronged but team approach with health care professionals, clinical and educational interventions, surveillance and monitoring procedures, and policy development.

\section{Minimizing Antibiotic Pressure}

The development of AMR is a natural phenomenon that occurs with or without exposure to antimicrobials. It is antibiotic pressure or antibiotic-induced natural selection that promotes and spreads resistant mutants. In contrast to common belief, AMR reversibility is a complex process affected by multiple factors. Although decreasing antibiotic pressure can reduce resistance levels, several studies have failed to demonstrate an impact on the individual or population level. ${ }^{185}$ However, it is understood that control of multidrug resistance (MDR) should involve limiting the use of homogeneous antimicrobials classes by maintaining prescribing diversity. ${ }^{186}$ Limitations on cost and drug availability can impact prescribing diversity. Therefore, there must be a multi-pronged emphasis in any strategy to curb AMR.

\section{Rational Prescribing and Use of Antimicrobial Agents}

The use of broad-spectrum antimicrobials by physicians and veterinarians is primarily attributed to the functional limitations in the rapid and reliable diagnosis of infectious disease, its causative organisms and the pathogens' susceptibility 
profile. Inadequate treatment for infections is related to poor outcomes, including higher morbidity and mortality and more extended stays in the health care facilities. ${ }^{104}$ Narrowing the spectrum of antibiotics and combining chemotherapeutic principles can improve efficacy, reduce toxicity and the overall cost of care, and prevent AMR in the population. ${ }^{186}$ Newer antibiotic drugs such as bedaquiline and modern fluoroquinolones have been reserved for MDR tuberculosis and need to be conserved to preserve their efficacy. The repurposing of withdrawn and underused antimicrobial drugs can provide an alternative or complementary approach to de-novo drug discovery and minimize cost and the impact of latency with new drug discovery and clinical trials. This is evident with the return of colistin and fosfomycin use for multidrug-resistant Gram-negative infections. ${ }^{186}$ The environment's antimicrobial contamination must be monitored at the policy level, and adequate safeguards must be put in place. ${ }^{185}$ The availability of antimicrobials in overthe-counter (OTC) preparations needs to be regulated, especially in low to middle-income countries. Irrational prescribing of antimicrobials may be a significant contributor to AMR due to self-diagnosis and access to OTC preparations, short duration of treatment and inappropriate choice of therapeutic class and dosage, lack of rapid microbiological diagnostic tools, physicians pressured by patients to prescribe antibiotics, and pharmaceutical pressure on physicians. ${ }^{187}$

\section{Genomic Engineering}

To monitor and treat widespread recalcitrant bacterial infections, the emergence of new bacterial genome engineering techniques offers promising diagnostic and treatment plans. Significant developments in genetic engineering techniques can effectively help target and alter pathogenic bacterial genomes to recognize and mitigate drug resistance mechanisms. ${ }^{188,189}$ The clustered regularly interspaced short palindromic repeats - CRISPR-associated (CRISPR-Cas) system, a bacterial adaptive immune system, is a newly recognized approach for controlling antibiotic-resistant strains, utilizing genomic engineering tools geared for gene knock-out and knock-in of sequence-specific DNA antibiotic targets. ${ }^{189-191}$ The system is aimed to neutralize "the invasion by foreign genetic material" such as, bacteriophages, plasmids and transposons where the CRISPR-Cas9 acts as a "RNA-guided-DNA cutter". Once foreign genetic material is encountered inside the bacteria, the Cas machinery barcodes small phage genome sequences into the genome of bacteria to assail it using the nuclease activity of CRISPRCas9 to cleave it. ${ }^{192,193}$ It can be programmed to specifically detect any DNA target provided in the CRISPR array such as specific virulence genes and antibiotic resistance coding genes in bacterial populations. ${ }^{194-197}$ This sequence-specific targeting ability allows it to discern between commensal and non-commensal bacterial species as it can be reused against the bacteria rather than defending against invaders as guide CRISPR-RNA can be constructed to target only chromosomal and virulence genes that are highly specific to pathogens. ${ }^{192,198}$ The elimination of bacterial virulence factors carried on virulence plasmids and resistance determinants in commensal bacteria has been carried out by the CRISPR/Cas9 "pro-active" genetic system (Pro-AG), a recently developed system. ${ }^{192,199}$ The enhanced cytotoxic potential is associated with the intentional or accidental targeting of the sequence of bacterial genome by Cas 9 nuclease, ${ }^{200}$ leading to apoptosis because of the introduction of irreversible chromosomal lesions. ${ }^{201,202}$ Therefore, a CRISPR-guided RNA can be fabricated to exclusively target resistance or virulence genes, reverting to antibiotic susceptible ones by inducing a break inside the dsDNA of resistant bacteria. $^{198}$

\section{Effective Vaccination Policies for the Greater Good}

Vaccines work by enabling the immune system to rapidly and efficiently identify and respond to a pathogen while mounting an immune response. While it is unlikely that vaccinations will protect against all the microbes contributing to the AMR, research and development prospects for vaccinations promise to mitigate AMR once proven efficacious, safe, and adequately implemented. There has been a decrease in the number of people and their children being vaccinated for different reasons, sometimes compromising an adequately implemented vaccination policy. ${ }^{203}$ Improper implementation of vaccination can create pathogen reservoirs within the population, which may become resistant to antimicrobials. Given the importance of vaccination for global health and AMR, it may become a matter of global interest to implement vaccination policies that cater to the population's greater good but limit the risk associated with declination of vaccines. ${ }^{204}$

\section{Clinical Treatment Strategies for Human and Animal Health}

The transfer of resistant microbes from animals to humans is well established, but antibiotics in animal husbandry as growth promoters continue to be unregulated. 
Plasmid-mediated colistin resistance was reported in China in 2015 and has been disseminated worldwide. Although colistin resistance was previously documented, there are significant epidemiological implications due to the plasmid-mediated nature of $\mathrm{mcr}-1$ (colistin resistance mechanism) gene resistance. ${ }^{205}$ Though compliance is not mandatory, the WHO has established a list of essential antimicrobials for human use, which is to be avoided in non-human interventions. ${ }^{206}$ It is likely that the list of essential antimicrobials for human use may become enforced to reduce AMR transfer from animals to humans or vice versa.

\section{Conclusion and Recommendations}

AMS' practices, principles, and interventions are critical steps towards containing and mitigating AMR. They are designed to promote, improve, monitor, and evaluate the rational use of antimicrobials to preserve their future effectiveness, along with the promotion and protection of public health. ASP has proven highly successful in promoting the rational use of antimicrobials through the implementation of evidence-based interventions. Its principles and core elements are embedded in the WHO Global Action Plan on AMR and should be factored in national strategies against AMR. The holistic and multisectoral "One Health" initiative is also needed to address AMR. The WHO recognized this global threat and strongly recommended implementing this approach at the national and global levels.

Moreover, at the healthcare system and organizational level, the implementation of an ASP is of utmost importance as it: i) transforms clinical and educational interventions, ii) facilitates the incorporation of new and more efficient diagnostic tools, iii) establishes AMR patterns through effective surveillance, and iv) reduces the cost of health-care expenditure by better outcomes in patients in clinical and veterinary settings.

Lastly, healthcare professionals must address the challenge of managing AMR's growing problem by leadership in human and veterinary medicine, pharmacy, and policy. The rational use of antimicrobials, "One Health" approach, vaccination protocols, healthcare workers' and patients' education, and the broader public awareness about AMR must be guided by strict evidence-based policy.

\section{Professionals Annotation}

AMR is one of the most persistent and tenacious public health perturbing issues. ${ }^{32,207}$ Globally, every year over two million drug-resistant infectious disease cases and 23,000 deaths were reported. 7,31,208 Irrational, imprudent prescribing and utilization of antimicrobials are considered top reasons for AMR, often blamed, and evidenced as an irresponsible act by healthcare professionals. ${ }^{32,209}$ AMR is increasingly accountable for difficulties and failures in managing infectious diseases. ${ }^{210,211}$ Furthermore, AMR consumes a significant share of the public healthcare budget, increases out-of-pocket expenses for patients, and increases financial burden towards communities. ${ }^{75,212,213}$ Lord J O'Neill and his group published a review appointed by the United Kingdom government titled, "Antimicrobial Resistance: Tackling a crisis for nations' health and wealth" in $2014 .^{214}$ They determined that AMR could result in 10 million dying per year with a cumulative cost of US $\$ 100$ trillion by $2050 .^{214,215}$ The situation is further aggravated by MDRO being amongst the topmost three dangers to international public health. ${ }^{216-219}$ Furthermore, the consumption of second-rate and counterfeit antimicrobials worldwide exacerbates the unnecessary, imprudent, irrational antimicrobials prescribing leading to MDR. ${ }^{32,220-225}$ Thereby, MDR is currently one of the most significant clinical challenges and is a pandemic in its merit. $^{32,143,226-228}$ AMR is increasing; however, the new antimicrobial drug development process has slowed down. ${ }^{229-231}$ Thereby, irrational, over, and redundant use of antimicrobials underwrites the advent of resistant microbes and the origins of patient impairment. Patients with AMR infections are more likely to experience treatment failure, repeated and persistent infection, prolonged hospitalization, postponed recovery, or succumbing to their infection. ${ }^{232,233}$ Contemporary research regarding antimicrobials and AMR highlights the necessity of diminishing imprudent use of antimicrobials in all health care facilities. ${ }^{18,32,234-237}$ According to the WHO:

AMR threatens the effective prevention and treatment of an ever-increasing range of infections caused by bacteria, parasites, viruses, and fungi. ${ }^{238}$ The $\mathrm{CDC}$ reported that $30-50 \%$ of all antimicrobials prescribed in the US acute care hospitals are irrational, imprudent, and superfluous. $^{239}$

Multiple research pieces reported that hospital-based ASPs improve antimicrobials prescribing patterns, infection control, and reduce adverse effects linked with antimicrobials consumption. ${ }^{64,240-243}$ ASPs refer to a set of synchronized and timely strategic action plans to ensure the judicious practice of antimicrobial use, ensuring and maximizing the patients' benefits and averting death. It 
also diminishes AMR, decreases redundant healthcare costs, and reduces the possibility of the MDR gene distribution within the microbial community. ${ }^{79,87,244-246}$ Moreover, ASPs supports physicians' progress in maximizing clinical benefits among their patients and minimizing adverse effects by improved correct prescribing, ie, appropriate antimicrobial selection, including adequate/ balanced spectrum; administration at the right time, in the right dose, by the appropriate route, and at proper time intervals. ${ }^{79,247}$

CDC, in 2019, restructured the fundamental rules and regulations of US hospitals regarding ASPs, which comprised: ${ }^{248}$ hospital leadership aptitude and obligation, answerability, pharmacy proficiency, actions promoting ideal antimicrobial use, surveillance of antimicrobial prescribing, consumption and AMR, and continued antimicrobial stewardship education. ${ }^{240,248,249}$ The ASPs are widely recognized as competent planning and policy implementation mechanisms to battle AMR's mounting threat. $^{79,250,251}$ There is also the widespread belief that antimicrobial stewardship is a team's determination to comprise all healthcare workers in the continuum of care. ASPs may vary by healthcare institutions; therefore, flexible and tailored approaches to local needs are essential. $^{252,253}$

Infection prevention and control, antimicrobial surveillance, and antimicrobial stewardship are believed to be the principal strategies for local, national, and international systems to prevent the development of AMR and reduce avoidable healthcare-associated infections (HCAIs). ${ }^{79,243,254}$ Public health professionals advocate ways to reduce pointless prescriptions to evade the onslaught of AMR. This becomes evident when there are high levels of antimicrobial use among COVID-19 patients, highlighting the necessity to institute stewardship agendas. ${ }^{26,28,102,255-257}$

AMR is a cumulative risk to global health safety. This can be countered possibly by increasing public health awareness worldwide. ${ }^{214}$ There is a need for a practical "One Health" approach to minimize imprudent or inappropriate use of antimicrobials, where local, national, and global action is required across human medicine, veterinary practice, and the agriculture sector. ${ }^{258}$ The critical recommendations put forward by renowned international organizations include the following: (i) increased use of vaccinations to reduce the need for antimicrobial agents, ${ }^{204,259}$ (ii) investment in the surveillance of AMR infections and sharing data to improve global responses, ${ }^{260,261}$ (iii) investment in research and development directed toward the development of innovative antimicrobial agents, vaccines, diagnostics and other tools to avert AMR, ${ }^{262}$ (iv) strengthen regulatory policies, agendas, and putting infection control and prevention methods in practice, ${ }^{263}(\mathrm{v})$ educate and train healthcare professionals on antimicrobial stewardship, ${ }^{177,264}$ (vi) facilitate the availability of antimicrobial agents only through a prescription provided by a certified health professional, ${ }^{219,265,266}$ (vii) healthcare professionals should strictly follow clinical and treatment guidelines to manage patients, ${ }^{267,268}$ (viii) increase awareness among the public regarding the harmful consequences of overuse and misuse of antimicrobial agents, ${ }^{269,270}$ (ix) more emphasis of antimicrobial stewardship in health professional curricula, ${ }^{271-273}$ (x) endorse and use hygienic practices and aseptic techniques at all stages of food handling and preparation whether from animal or plant sources ${ }^{274-277}$ and (xi) promote and ensure adherence to hygiene measures and other infection prevention practices ${ }^{278-283}$ eg washing hands, cooking food hygienically, evading close contact with infectious disease people, practicing safer sex, and keeping vaccinations up to date.

\section{Article Highlights}

- AMR is a significant urgent threat to global public health, responsible for increased morbidity and mortality and high economic burden.

- MDR bacteria and COVID-19 pandemic also have substantial implications on clinical and economic outcomes by increasing higher rate of AMR.

- AMS aims to optimize antimicrobial use, and AMS practices, principles, and interventions are critical steps towards containing and mitigating AMR.

- ASP has been widely employed and proven to improve the appropriate use of antimicrobials by implementing evidence-based interventions.

- "One Health" approach, a holistic and multisectoral approach, is also widely recommended to address the rising threat of AMR by implementing aligned AMS strategies at the individual, the national, and global levels, and across human health, animal health, and the environment.

- The rational use of antimicrobials, "One Health" approach, vaccination protocols, and education and training about AMR must be guided by evidencebased policies and guidelines prescribed by national and international organizations. 


\section{Consent for Publication}

All authors reviewed and approved the final version and have agreed to be accountable for all aspects of the work, including any issues related to accuracy or integrity.

\section{Acknowledgment}

The authors wish to thank Dr. Massimo Sartelli MD, Acting Director, Global Alliance for Infections in Surgery, and Dr. Caitlin Mollison, Managing Editor, of Pharmacy Times, for their permission to use Figure 1 and Box 4 respectively in this paper.

\section{Author Contributions}

All authors made a significant contribution to the work reported, whether that is in the conception, study design, execution, acquisition of data, analysis, and interpretation, or in all these areas; took part in drafting, revising or critically reviewing the article; gave final approval of the version to be published; have agreed on the journal to which the article has been submitted; and agree to be accountable for all aspects of the work.

\section{Funding}

This paper was not funded.

\section{Disclosure}

Dr. Md Anwarul Azim Majumder is the Editor-in-Chief of Advances in Medical Education and Practice with Dove Medical Press. All authors have no relevant affiliations or financial involvement with any organization or entity with a financial interest in or financial conflict with the subject matter or materials discussed in the manuscript. This includes employment, consultancies, honoraria, stock ownership or options, expert testimony, grants or patents received or pending, or royalties.

\section{References}

1. World Health Organization. Record number of countries contribute data revealing disturbing rates of antimicrobial resistance; 2020. Available from: https://www.who.int/news-room/detail/01-062020-record-number-of-countries-contribute-data-revealing-disturb ing-rates-of-antimicrobial-resistance. Accessed December 9, 2020.

2. World Health Organization. 2020 Antibiotic resistance; 2020. Available from: https://www.who.int/news-room/fact-sheets/detail/anti biotic-resistance. Accessed December 9, 2020.

3. Centers for Disease Control and Prevention. Antibiotic/Antimicrobial Resistance (AR/AMR); 2020. https://www.cdc.gov/drugresistance/ index.html. Accessed December 9, 2020.
4. World Medical Association (WMA). WMA statement on antimicrobial resistance. Available from: https://www.wma.net/policies-post/ wma-statement-on-resistance-to-antimicrobial-drugs/. Accessed December 9, 2020.

5. World Health Organization. Turning Plans into Action for Antimicrobial Resistance (AMR). Working Paper 2.0: Implementation and Coordination. Geneva: World Health Organization; 2019.

6. Public Health Group. Tackling Antimicrobial Resistance 20192024: The UK's Five-Year National Action Plan. London: HM Government; 2019.

7. Dadgostar P. Antimicrobial resistance: implications and costs. Infect Drug Resist. 2019;12:3903-3910. doi:10.2147/IDR.S234610

8. Buchy P, Ascioglu S, Buisson Y, et al. Impact of vaccines on antimicrobial resistance. Int $J$ Infect Dis. 2020;90:188-196. doi:10.1016/j.ijid.2019.10.005

9. ISGlobal. Antimicrobial resistance. Available from: https://www.isglo bal.org/en/antimicrobial-resistance. Accessed December 9, 2020.

10. Centers for Disease Control and Prevention. 2020. About antibiotic resistance. Available from: https://www.cdc.gov/drugresis tance/about.html. Accessed December 9, 2020.

11. World Health Organization. Global Antimicrobial Resistance Surveillance System (GLASS) Report: Early Implementation. Geneva: World Health Organization; 2020.

12. Lushniak BD. Antibiotic resistance: a public health crisis. Public Health Rep. 2014;129(4):314-316. doi:10.1177/0033354914129 00402

13. Centers for Disease Control and Prevention. CDC, office of infectious disease; 2020. Available from: https://www.cdc.gov/ drugresistance/biggest-threats.html?CDC_AA_refVal=https $\% 3 \mathrm{~A}$ $\% 2 \mathrm{~F} \% 2 \mathrm{Fwww} . c d c . g o v \% 2 \mathrm{Fdrugresistance} \% 2 \mathrm{Fbiggest}$ threats. html. Accessed December 9, 2020.

14. World Bank. By 2050, drug-resistant infections could cause global economic damage on par with 2008 financial crisis. World Bank; 2016. Available from: https://www.worldbank.org/en/news/ press-release/2016/09/18/by-2050-drug-resistant-infectionscould-cause-global-economic-damage-on-par-with-2008-finan cial-crisis. Accessed December 9, 2020.

15. Interagency Coordination Group on Antimicrobial Resistance. No time to wait: securing the future from drug-resistant infections report to the secretary-general of the United Nations; 2019. Available from: https://www.who.int/antimicrobial-resistance/ interagency-coordination-group/IACG_final_report_EN.pdf?ua= 1. Accessed December 9, 2020.

16. World Health Organization. Antimicrobial Resistance. Available from: https://www.euro.who.int/en/health-topics/disease-preven tion/antimicrobial-resistance. Accessed December 9, 2020.

17. Ventola CL. The antibiotic resistance crisis: part 1: causes and threats. Pharm Therap. 2015;40(4):277-283.

18. Aslam B, Wang W, Arshad MI, et al. Antibiotic resistance: a rundown of a global crisis. Infect Drug Resist. 2018;11:16451658. doi:10.2147/IDR.S173867

19. Centers for Disease Control and Prevention. Antibiotic Resistance Threats in the United States, 2019. Atlanta, GA: U.S. Department of Health and Human Services; 2019.

20. Santajit $S$, Indrawattana N. Mechanisms of antimicrobial resistance in ESKAPE pathogens. Biomed Res Int. 2016;2016: 2475067. doi:10.1155/2016/2475067

21. World Health Organization. Global Tuberculosis Report. Geneva: World Health Organization; 2019.

22. World Health Organization. Global Tuberculosis Report. Geneva: World Health Organization; 2015.

23. European Centre for Disease Prevention and Control \& World Health Organization Regional Office for Europe. Tuberculosis Surveillance and Monitoring in Europe 2019 - 2017 Data. Copenhagen: European Centre for Disease Prevention and Control; 2019. 
24. World Health Organization. Clinical management of COVID-19 interim guidance - May 2020. Geneva: World Health Organization; 2020. Available from: https://www.who.int/publications-detail/clini cal-management-of-covid-19. Accessed December 9, 2020.

25. The Guardian. World Health Organization warns overuse of antibiotics for Covid-19 will cause more deaths; 2020. Available from: https://www.theguardian.com/world/2020/jun/01/whowarns-overuse-of-antibiotics-for-covid-19-will-cause-moredeaths. Accessed December 9, 2020.

26. Getahun H, Smith I, Trivedi K, Paulin S, Balkhy HH. Tackling antimicrobial resistance in the COVID-19 pandemic. Bull World Health Organ. 2020;98(7):442-442A. doi:10.2471/BLT.20.268573

27. Rawson TM, Moore LSP, Zhu N, et al. Bacterial and fungal coinfection in individuals with coronavirus: a rapid review to support COVID-19 antimicrobial prescribing. Clin Infect Dis. 2020; ciaa530. doi:10.1093/cid/ciaa530

28. Murray AK. The Novel Coronavirus COVID-19 outbreak: global implications for antimicrobial resistance. Front Microbiol. 2020;11:1020. doi:10.3389/fmicb.2020.01020

29. Hsu J. How covid-19 is accelerating the threat of antimicrobial resistance. BMJ. 2020;369:m1983. doi:10.1136/bmj.m1983

30. Saleem Z, Godman B, Hassali MA, Hashmi FK, Azhar F, Rehman IU. Point prevalence surveys of health-care-associated infections: a systematic review. Pathog Glob Health. 2019;113 (4):191-205. doi:10.1080/20477724.2019.1632070

31. Toner E, Adalja A, Gronvall GK, Cicero A, Inglesby TV. Antimicrobial resistance is a global health emergency. Health Secure. 2015;13(3):153-155. doi:10.1089/hs.2014.0088

32. Prestinaci F, Pezzotti P, Pantosti A. Antimicrobial resistance: a global, multifaceted phenomenon. Pathog Glob Health. 2015;109 (7):309-318. doi:10.1179/2047773215Y.0000000030

33. World Health Organization. Antibacterial Agents in Clinical Development: An Analysis of the Antibacterial Clinical Development Pipeline. Geneva: World Health Organization; 2019.

34. World Health Organization. Antibacterial Agents in Preclinical Development: An Open-Access Database. Geneva: World Health Organization; 2019.

35. World Health Organization. Lack of new antibiotics threatens global efforts to contain drug-resistant infections; 2020. Available from: https://www.who.int/news-room/detail/17-012020-17-01-2020-lack-of-new-antibiotics-threatens-globalefforts-to-contain-drug-resistant-infections. Accessed December 9, 2020.

36. World Intellectual Property Organization (WIPO). Standing Committee on the Law of Patents. Review of Existing Research on Patents and Access to Medical Products and Health Technologies. Geneva: Thirty-First session; 2019.

37. AMR Industry Alliance. AMR Industry Alliance, 2020 Progress Report. Geneva: AMR Industry Alliance; 2020.

38. Ridge KW, Hand K, Sharland M, Abubakar I, Livermore DM. Antimicrobial resistance. In: Davies SC, editor. Annual Report of the Chief Medical Officer, Volume Two, 2011, Infections and the Rise of Antimicrobial Resistance. London: Department of Health; 2013.

39. Dellit TH, Owens RC, McGowan JE, et al. Infectious Diseases Society of America and the Society for Healthcare Epidemiology of America guidelines for developing an institutional program to enhance antimicrobial stewardship. Clin Infect Dis. 2007;44 (2):159-177. doi:10.1086/510393

40. Donà $\mathrm{D}$, Barbieri $\mathrm{E}$, Daverio $\mathrm{M}$, et al. Implementation and impact of pediatric antimicrobial stewardship programs: a systematic scoping review. Antimicrob Resist Infect Control. 2020;9:3. doi:10.1186/s13756-019-0659-3

41. Dik JW, Hendrix R, Poelman R, et al. Measuring the impact of antimicrobial stewardship programs. Expert Rev Anti Infect Ther. 2016;14(6):569-575. doi:10.1080/14787210.2016.1178064
42. Rosenblatt-Farrell N. The landscape of antibiotic resistance. Environ Health Perspect. 2009;117(6):A244-A250. doi:10.1289/ ehp.117-a244

43. McGowan JE, Gerding DN. Does antibiotic restriction prevent resistance? New Horiz. 1996;4(3):370-376.

44. Shlaes DM, Gerding DN, John JF, et al. Society for Healthcare Epidemiology of America and Infectious Diseases Society of America Joint Committee on the prevention of antimicrobial resistance: guidelines for the prevention of antimicrobial resistance in hospitals. Clin Infect Dis. 1997;25(3):584-599. doi:10.1086/513766

45. Goff DA, Kullar R, Goldstein EJC, et al. A global call from five countries to collaborate in antibiotic stewardship: united we succeed, divided we might fail. Lancet Infect Dis. 2017;17(2):e56e63. doi:10.1016/S1473-3099(16)30386-3

46. Dyar OJ, Huttner B, Schouten J, Pulcini C; ESGAP (ESCMID Study Group for Antimicrobial stewardship). What is antimicrobial stewardship? Clin Microbiol Infect. 2017;23(11):793-798. doi:10.1016/j.cmi.2017.08.026

47. Centers for Disease Control and Prevention. Antibiotic prescribing and use in hospitals and long-term care; 2017. Available from: https:// www.cdc.gov/antibiotic-use/healthcare/\#: : :text=Studies\%20demon strate $\% 20$ that $\% 20$ improving\%20prescribing,all\%20while\%20redu cing\%20healthcare\%20costs. Accessed December 9, 2020.

48. Davey P, Marwick CA, Scott CL, et al. Interventions to improve antibiotic prescribing practices for hospital inpatients. Cochrane Database Syst Rev. 2017;2(2):CD003543. doi:10.1002/14651858. CD003543.pub4

49. Gregory JR, Suleyman S, Barnes MN. A review of the opportunities and shortcomings of antibiotic stewardship. US Pharm. 2018;43(4):HS-7-HS-12.

50. Pollack LA, van Santen KL, Weiner LM, Dudeck MA, Edwards JR, Srinivasan A. Antibiotic stewardship programs in U.S. acute care hospitals: findings from the 2014 national healthcare safety network annual hospital survey. Clin Infect Dis. 2016;63(4):443449. doi:10.1093/cid/ciw323

51. Joint Commission on Hospital Accreditation. APPROVED: new antimicrobial stewardship standard. J Comm Perspect. 2016;36 (7): $1,3-4,8$.

52. Oberjé EJM, Tanke MAC, Jeurissen PPT. Antimicrobial stewardship initiatives throughout europe: proven value for money. Infect Dis Rep. 2017;9(1):6800. doi:10.4081/idr.2017.6800

53. European Commission. EU guidelines for the prudent use of antimicrobials in human health (2017/C 212/01). ECDC. Brussels: European Commission. Available from: https://eur-lex.europa.eu/legal-content/ EN/TXT/PDF/?uri=CELEX:52017XC0701(01)\&from=EN. Accessed December 9, 2020.

54. European Centre for Disease Prevention and Control. Proposals for EU guidelines on the prudent use of antimicrobials in humans. Stockholm: ECDC; 2017. Available from: https://www.ecdc.europa. $\mathrm{eu} /$ sites/portal/files/media/en/publications/Publications/EU-guide lines-prudent-use-antimicrobials.pdf. Accessed December 9, 2020.

55. Saam M, Huttner B, Harbarth S Evaluation of antibiotic awareness campaigns. WHO collaborating centre on patient safety. Geneva, Switzerland: The University of Geneva Hospitals and Faculty of Medicine; 2017. Available from: https://www.who.int/selection_medi cines/committees/expert/21/applications/s6_antibiotic_awareness_ campaigns.pdf?ua=1. Accessed December 9, 2020.

56. Kpokiri EE, Taylor DG, Smith FJ. Development of antimicrobial stewardship programmes in low and middle-income countries: a mixed-methods study in Nigerian hospitals. Antibiotics (Basel). 2020;9(4):204. doi:10.3390/antibiotics9040204

57. Cox JA, Vlieghe E, Mendelson M, et al. Antibiotic stewardship in low- and middle-income countries: the same but different? Clin Microbiol Infect. 2017;23(11):812-818. doi:10.1016/j.cmi.2017. 07.010 
58. Van Dijck C, Vlieghe E, Cox JA. Antibiotic stewardship interventions in hospitals in low-and middle-income countries: a systematic review. Bull World Health Organ. 2018;96(4):266-280. doi:10.2471/BLT.17.203448

59. Wilkinson A, Ebata A, MacGregor H. Interventions to reduce antibiotic prescribing in LMICs: a scoping review of evidence from human and animal health systems. Antibiotics (Basel). 2018;8(1):2. doi:10.3390/antibiotics8010002

60. Septimus EJ, Owens RC. Need and potential of antimicrobial stewardship in community hospitals. Clin Infect Dis. 2011;53 (Suppl 1):S8-S14. doi:10.1093/cid/cir363

61. United Nations. Political declaration of the high-level meeting of the general assembly on antimicrobial resistance; 2016. Available from: https://digitallibrary.un.org/record/842813?ln=en. Accessed December 9, 2020.

62. World Health Organization. Global action plan on antimicrobial resistance. 20 Avenue Appia, 1211 Geneva 27, Switzerland: World Health Organization. WHO Press, World Health Organization; 2015. Available from: https://apps.who.int/iris/bit stream/handle/10665/193736/9789241509763_eng.pdf? sequence $=1$. Accessed December 9, 2020 .

63. World Health Organization. Antimicrobial stewardship programs in health-care facilities in low- and middle-income countries: a WHO practical toolkit. World Health Organization; 2019. Available from: https:/apps.who.int/iris/bitstream/handle/10665/ 329404/9789241515481-eng.pdf? sequence $=1$ \&isAllowed $=\mathrm{y}$. Accessed December 9, 2020.

64. MacDougall C, Polk RE. Antimicrobial stewardship programs in health care systems. Clin Microbiol Rev. 2005;18(4):638-656. doi:10.1128/CMR.18.4.638-656.2005

65. Liaskou M, Duggan C, Joynes R. Pharmacy's role in antimicrobial resistance and stewardship. Clin Pharm. 2018;10:6. doi:10.1211/CP.2018.20204885

66. Society for Healthcare Epidemiology of America; Infectious Diseases Society of America; Pediatric Infectious Diseases Society. Policy statement on antimicrobial stewardship by the Society for Healthcare Epidemiology of America (SHEA), the Infectious Diseases Society of America (IDSA), and the Pediatric Infectious Diseases Society (PIDS). Infect Control Hosp Epidemiol. 2012;33(4):322-327. doi:10.1086/ 665010.

67. Lloyd DH, Page SW. Antimicrobial stewardship in veterinary medicine. Microbiol Spectr. 2018;6(3). doi:10.1128/microbiolspec.ARBA-0023-2017

68. The Society for Healthcare Epidemiology of America. Infection prevention and control programs are essential to antibiotic stewardship efforts; 2018. Available from: https:// www.shea-online.org/index.php/journal-news/press-room/pressrelease-archives/581-infection-prevention-and-control-pro grams-are-essential-to-antibiotic-stewardship-efforts\#: :text= Antimicrobial $\% 20$ stewardship $\% 20$ programs $\% 20$ encourage $\%$ 20the,preserve $\% 20$ the $\% 20$ efficacy $\% 20$ of $\% 20$ antibiotics. Accessed December 9, 2020.

69. Global Alliance for Infections in Surgery for Infections in Surgery. Core elements of antibiotic stewardship. Available from: https://infectionsinsurgery.org/core-elements-of-antibioticstewardship/. Accessed December 9, 2020.

70. Bondarenka CM, Bosso JA. Successful implementation of an antimicrobial stewardship program at an academic medical center. Hosp Pharm. 2017;52(7):508-513. doi:10.1177/0018578717721 535

71. Centers for Disease Control and Prevention. CDC, the core elements of hospital antibiotic stewardship programs; 2019. Available from:https://www.cdc.gov/antibiotic-use/core-elements/ hospital.html. Accessed December 9, 2020.
72. Tang K, Heil EL Antimicrobial stewardship: a primer for hospital pharmacists. Pharmacy Times; 2016. Available from: https:// www.pharmacytimes.com/publications/health-system-edition/ 2016/march2016/antimicrobial-stewardship-a-primer-for-hospi tal-pharmacists. Accessed December 9, 2020.

73. Ostrowsky B, Banerjee R, Bonomo RA, et al. Infectious Diseases Society of America, Pediatric Infectious Diseases Society, and the Society for Healthcare Epidemiology of America. Infectious diseases physicians: leading the way in antimicrobial stewardship. Clin Infect Dis. 2018;66(7):995-1003. doi:10.1093/cid/cix1093

74. Trivedi KK, Pollack LA. The role of public health in antimicrobial stewardship in healthcare. Clin Infect Dis. 2014;59(Suppl 3): S101-S103. doi:10.1093/cid/ciu544

75. Anderson M, Clift C, Schulze K, et al. Averting the AMR crisis: what are the avenues for policy action for countries in Europe? [Internet] Copenhagen (Denmark): European Observatory on Health Systems and Policies; 2019. Available from: https:/www.ncbi.nlm.nih.gov/ books/NBK543407/. Accessed December 9, 2020.

76. Gai Z, Samodelov SL, Kullak-Ublick GA, Visentin M. Molecular mechanisms of colistin-induced nephrotoxicity. Molecules. 2019;24(3):653. doi:10.3390/molecules24030653

77. Mulani MS, Kamble EE, Kumkar SN, Tawre MS, Pardesi KR. Emerging strategies to combat ESKAPE pathogens in the era of antimicrobial resistance: a review. Front Microbiol. 2019;10:539. doi:10.3389/fmicb.2019.00539

78. Rice LB. Progress and challenges in implementing the research on ESKAPE pathogens. Infect Control Hosp Epidemiol. 2010;31 (Suppl 1):S7-S10. doi:10.1086/655995

79. Doron S, Davidson LE. Antimicrobial stewardship. Mayo Clin Proc. 2011;86(11):1113-1123. doi:10.4065/mcp.2011.0358

80. Joseph J, Rodvold KA. The role of carbapenems in the treatment of severe nosocomial respiratory tract infections. Expert Opin Pharmacother. 2008;9(4):561-575. doi:10.1517/14656566.9.4.561

81. Public Health Foundation. Public health antibiotic stewardship driver diagram; 2013. Available from: http://www.phf.org/resour cestools/Documents/Antibiotic_Stewardship_Driver_Diagram. pdf. Accessed December 9, 2020.

82. Centers for Disease Control and Prevention. The 10 essential public health services; 2020. Available from: https://phnci.org/uploads/ resource-files/EPHS-English.pdf. Accessed December 9, 2020.

83. Talbot GH, Das A, Cush S, et al. Foundation for the National Institutes of Health Biomarkers Consortium HABP/VABP Project Team. Evidence-based study design for hospital-acquired bacterial pneumonia and ventilator-associated bacterial pneumonia. $J$ Infect Dis. 2019;219(10):1536-1544. doi:10.1093/infdis/jiy578

84. Bertollo LG, Lutkemeyer DS, Levin AS. Are antimicrobial stewardship programs effective strategies for preventing antibiotic resistance? A systematic review. Am J Infect Control. 2018;46 (7):824-836. doi:10.1016/j.ajic.2018.01.002

85. Standiford HC, Chan S, Tripoli M, Weekes E, Forrest GN. Antimicrobial stewardship at a large tertiary care academic medical center: cost analysis before, during, and after a 7-year program. Infect Control Hosp Epidemiol. 2012;33(4):338-345. doi:10.1086/664909

86. Combes JR, Arespacochaga E, Appropriate use of medical resources. Chicago, IL: American Hospital Association's Physician Leadership Forum; 2013. Available from: http://www. ahaphysicianforum.org/files/pdf/appropusewhiteppr.pdf. Accessed December 9, 2020.

87. File TM, Srinivasan A, Bartlett JG. Antimicrobial stewardship: importance for patient and public health. Clin Infect Dis. 2014;59 (Suppl 3):S93-S96. doi:10.1093/cid/ciu543

88. Forde C, Stierman B, Ramon-Pardo P, Dos Santos T, Singh N. Carbapenem-resistant Klebsiella pneumoniae in Barbados: driving change in practice at the national level. PLoS One. 2017;12 (5):e0176779. doi:10.1371/journal.pone.0176779 
89. Cassini A, Högberg LD, Plachouras D, et al. Attributable deaths and disability-adjusted life-years caused by infections with antibiotic-resistant bacteria in the EU and the European Economic Area in 2015: a population-level modeling analysis. Lancet Infect Dis. 2019;19(1):56-66. doi:10.1016/S1473-3099(18)30605-4

90. Holmes EAF, Hughes DA. Challenges for economic evaluation of health care strategies to contain antimicrobial resistance. Antibiotics (Basel). 2019;8(4):166. doi:10.3390/antibiotics804 0166

91. Centers for Disease Control and Prevention. Antibiotic resistance threats in the United States 2013. Atlanta, GA: U.S. Department of Health and Human Services. Available from: https://www.cdc. gov/drugresistance/Threat-Report-2013/pdf/ar-Threats-2013-508. pdf. Accessed December 9, 2020.

92. Nagpal R, Mainali R, Ahmadi S, et al. Gut microbiome and aging: physiological and mechanistic insights. Nutr Healthy Aging. 2018;4(4):267-285. doi:10.3233/NHA-170030

93. World Health Organization. Global antimicrobial resistance surveillance system (GLASS): technical meeting on the early implementation phase: 22-23 October 2015. WHO Regional Office for Europe Copenhagen, Denmark: meeting report. World Health Organization. Available from: https://apps.who.int/iris/handle/ 10665/204117. Accessed December 9, 2020.

94. World Health Organization. GLASS report: early implementation, 2017-2018; 2018. Geneva: World Health Organization. Available from: https://apps.who.int/iris/bit stream/handle/10665/279656/9789241515061-eng.pdf?ua=1. Accessed December 9, 2020.

95. McLeod M, Ahmad R, Shebl NA, Micallef C, Sim F, Holmes A. A whole-health-economy approach to antimicrobial stewardship: analysis of current models and future direction. PLoS Med. 2019;16(3):e1002774. doi:10.1371/journal.pmed.1002774

96. Aldeyab MA, Harbarth S, Vernaz N, et al. The impact of antibiotic use on the incidence and resistance pattern of extendedspectrum beta-lactamase-producing bacteria in primary and secondary healthcare settings. Br J Clin Pharmacol. 2012;74 (1):171-179. doi:10.1111/j.1365-2125.2011.04161

97. World Health Organization. One health. In: World Health Organization [Internet]. World Health Organization; 2017. Available from: http://www.who.int/features/qa/one-health/en/. Accessed December 9, 2020.

98. Hardefeldt LY, Gilkerson JR, Billman-Jacobe H, et al. Barriers to and enablers of implementing antimicrobial stewardship programs in veterinary practices. $J$ Vet Intern Med. 2018;32 (3):1092-1099. doi:10.1111/jvim.15083

99. Charani E, Edwards R, Sevdalis N, et al. Behavior change strategies to influence antimicrobial prescribing in acute care: a systematic review. Clin Infect Dis. 2011;53(7):651-662. doi: $10.1093 / \mathrm{cid} / \mathrm{cir} 445$

100. Charani E, Castro-Sanchez E, Sevdalis N, et al. Understanding the determinants of antimicrobial prescribing within hospitals: the role of "prescribing etiquette". Clin Infect Dis. 2013;57(2):188196. doi:10.1093/cid/cit212

101. MacFadden DR, McGough SF, Fisman D, Santillana M, Brownstein JS. Antibiotic resistance increases with local temperature. Nat Clim Chang. 2018;8(6):510-514. doi:10.1038/s41558018-0161-6

102. Ohl CA, Luther VP. Health care provider education as a tool to enhance antibiotic stewardship practices. Infect Dis Clin North Am. 2014;28(2):177-193. doi:10.1016/j.idc.2014.02.001

103. British Society for Antimicrobial Chemotherapy. Antimicrobial stewardship from principles to practice. Birmingham, UK: British Society for Antimicrobial Chemotherapy, BSAC; 2018. Available from: http://www.bsac.org.uk/antimicrobialstewardshipebook/ BSAC-AntimicrobialStewardship-FromPrinciplestoPracticeeBook.pdf. Accessed December 9, 2020.
104. Leekha S, Terrell CL, Edson RS. General principles of antimicrobial therapy. Mayo Clin Proc. 2011;86(2):156-167. doi:10.40 65/mcp.2010.0639

105. Melander RJ, Zurawski DV, Melander C. Narrow-spectrum antibacterial agents. Medchemcomm. 2018;9(1):12-21. doi:10.1039/ C7MD00528H

106. Hembach N, Schmid F, Alexander J, Hiller C, Rogall ET, Schwartz T. Occurrence of the mcr-1 colistin resistance gene and other clinically relevant antibiotic resistance genes in microbial populations at different municipal wastewater treatment plants in Germany. Front Microbiol. 2017;8:1282. doi:10.3389/ fmicb.2017.01282

107. Wright GD. Antibiotic adjuvants: rescuing antibiotics from resistance. Trends Microbiol. 2016;24(11):928. doi:10.1016/j.tim.20 16.07 .008

108. Laws M, Shaaban A, Rahman KM. Antibiotic resistance breakers: current approaches and future directions. FEMS Microbiol Rev. 2019;43(5):490-516. doi:10.1093/femsre/fuz014

109. Liu Y, Li R, Xiao X, Wang Z. Antibiotic adjuvants: an alternative approach to overcome multi-drug resistant Gram-negative bacteria. Crit Rev Microbiol. 2019;45(3):301-314. doi:10.1080/ 1040841X.2019.1599813

110. Tang H, Zhao W, Yu J, Li Y, Zhao C. Recent development of pHresponsive polymers for cancer nanomedicine. Molecules. 2018;24(1):4. doi:10.3390/molecules24010004

111. González-Bello C. Antibiotic adjuvants - A strategy to unlock bacterial resistance to antibiotics. Bioorg Med Chem Lett. 2017;27 (18):4221-4228. doi:10.1016/j.bmcl.2017.08.027

112. Douafer H, Andrieu V, Phanstiel O, Brunel JM. Antibiotic adjuvants: make antibiotics great again! J Med Chem. 2019;62 (19):8665-8681. doi:10.1021/acs.jmedchem.8b01781

113. Gill EE, Franco OL, Hancock RE. Antibiotic adjuvants: diverse strategies for controlling drug-resistant pathogens. Chem Biol Drug Des. 2015;85(1):56-78. doi:10.1111/cbdd.12478

114. Hawkey PM, Warren RE, Livermore DM, et al. Treatment of infections caused by multidrug-resistant Gram-negative bacteria: report of the British Society for Antimicrobial Chemotherapy/ Healthcare Infection Society/British Infection Association Joint Working Party. J Antimicrob Chemother. 2018;73(Suppl_3):iii2iii78. doi:10.1093/jac/dky027

115. Nathwani D, Sneddon J. Practical Guide to Antimicrobial Stewardship in Hospitals. Durham, USA: Biomerieux Inc; 2015.

116. Bloomfield SF, Cookson B, Falkiner F, Griffith C, Cleary V. Methicillin-resistant Staphylococcus aureus, Clostridium difficile, and extended-spectrum beta-lactamase-producing Escherichia coli in the community: assessing the problem and controlling the spread. Am J Infect Control. 2007;35(2):86-88. doi:10.1016/j.ajic.2006.10.003

117. Matsuura GT, Garrison MW. Antibiotic collateral damage: resistance and antibiotic-associated diarrhea. Hosp Pharm. 2011;46:758-768.

118. Laplante K, Cunha C, Morrill H, Rice L, Mylonakis E. Antimicrobial Stewardship: Principles and Practice. Boston: CAB International; 2017.

119. de Jong LAW, van der Linden PD, Roukens MMB, van de Garde EMW, van der Velden AW, Natsch S. Consecutive antibiotic use in the outpatient setting: an extensive, longitudinal descriptive analysis of antibiotic dispensing data in the Netherlands. $B M C$ Infect Dis. 2019;19(1):84. doi:10.1186/s12879-019-3732-x

120. Cunha BA. Effective antibiotic-resistance control strategies. Lancet. 2001;357(9265):1307-1308. doi:10.1016/S0140-6736 (00)04527-X

121. Gasparetto J, Tuon FF, Dos Santos Oliveira D. Intravenous-tooral antibiotic switch therapy: a cross-sectional study in critical care units. BMC Infect Dis. 2019;19(1):650. doi:10.1186/s12879019-4280-0 
122. Vogtländer NP, Van Kasteren ME, Natsch S, Kullberg BJ, Hekster YA, Van Der Meer JW. Improving the process of antibiotic therapy in daily practice: interventions to optimize timing, dosage adjustment to renal function, and switch therapy. Arch Intern Med. 2004;164(11):1206-1212. doi:10.1001/archinte.164.11.1206

123. Barlam TF, Cosgrove SE, Abbo LM, et al. Executive summary: implementing an antibiotic stewardship program: guidelines by the Infectious Diseases Society of America and the Society for Healthcare Epidemiology of America. Clin Infect Dis. 2016;62 (10):1197-1202. doi:10.1093/cid/ciw217

124. Cunha CB. Antimicrobial stewardship programs: principles and practice. Med Clin North Am. 2018;102(5):797-803. doi:10.1016/ j.mcna.2018.04.003

125. Simoens S. Factors affecting the cost-effectiveness of antibiotics. Chemother Res Pract. 2011;2011:249867. doi:10.1155/2011/ 249867

126. Saliba-Gustafsson EA, Dunberger Hampton A, Zarb P, Orsini N, Borg MA, Stålsby Lundborg C. Factors associated with antibiotic prescribing in patients with acute respiratory tract complaints in Malta: a 1-year repeated cross-sectional surveillance study. $B M J$ Open. 2019;9(12):e032704. doi:10.1136/bmjopen-2019-032704

127. Institute for Healthcare Improvement, Centers for Disease Control. Antibiotic stewardship drivers and change package [Internet]. Atlanta, GA: US Department of Health and Human Services, CDC; 2012. Available from: http://www.cdc.gov/gets mart/healthcare/pdfs/antibiotic_stewardship_change_package.pdf. Accessed December 9, 2020.

128. Septimus E Get smart for healthcare. Clinician guide for collecting cultures. Atlanta, GA: US Department of Health and Human Services. CDC; 2015. Available from: http://www.cdc.gov/gets mart/healthcare/implementation/clinicianguide.html. Accessed December 9, 2020.

129. Waters CD. Pharmacist-driven antimicrobial stewardship program in an institution without infectious diseases physician support. $\mathrm{Am}$ $J$ Health Syst Pharm. 2015;72(6):466-468. doi:10.2146/ajhp14 0381

130. Bowater RJ, Stirling SA, Lilford RJ. Is antibiotic prophylaxis in surgery a generally effective intervention? Testing a generic hypothesis over a set of meta-analyses. Ann Surg. 2009;249 (4):551-556. doi:10.1097/SLA.0b013e318199f202

131. Bratzler DW, Dellinger EP, Olsen KM, et al. Clinical practice guidelines for antimicrobial prophylaxis in surgery. Am J Health Syst Pharm. 2013;70(3):195-283. doi:10.2146/ajhp120568

132. Roberts JA, Norris R, Paterson DL, Martin JH. Therapeutic drug monitoring of antimicrobials. Br J Clin Pharmacol. 2012;73 (1):27-36. doi:10.1111/j.1365-2125.2011

133. Rybak MJ, Lomaestro BM, Rotschafer JC, et al. Vancomycin therapeutic guidelines: a summary of consensus recommendations from the infectious diseases Society of America, the American Society of Health-System Pharmacists, and the Society of Infectious Diseases Pharmacists. Clin Infect Dis. 2009;49 (3):325-327. doi:10.1086/600877

134. Flanders SA, Saint S. Why does antimicrobial overuse in hospitalized patients persist? JAMA Intern Med. 2014;174(5):661-662. doi:10.1001/jamainternmed.2014.897

135. Hughes SJ, Moore LS. Antimicrobial stewardship. Br J Hosp Med (Lond). 2019;80(3):C42-C45. doi:10.12968/hmed.2019. 80.3.C42

136. Kim J, Craft DW, Katzman M. Building an antimicrobial stewardship program: cooperative roles for pharmacists, infectious diseases specialists, and clinical microbiologists. Lab Med. 2015;46 (3):e65-e71. doi:10.1309/LMCOSHRJBY0ONHI9

137. Mas-Morey P, Valle M. A systematic review of inpatient antimicrobial stewardship programs involving clinical pharmacists in small-to-medium-sized hospitals. Eur J Hosp Pharm. 2018;25 (e1):e69-e73. doi:10.1136/ejhpharm-2017-001381
138. Ladenheim D. Role of nurses in supporting antimicrobial stewardship. Nurs Stand. 2018;33(6):55-58. doi:10.7748/ns

139. Shaukat A, Al-Wali W, Nawash E, Sonallah H. Antimicrobial stewardship: a shared responsibility among primary prescribers, pharmacists, infectious disease physicians, and microbiologists. $J$ Infect Dis Ther. 2020;8:420.

140. Kullar R, Yang H, Grein J, Murthy R. A roadmap to implementing antimicrobial stewardship principles in Long-term Care Facilities (LTCFs): collaboration between an acute-care hospital and LTCFs. Clin Infect Dis. 2018;66(8):1304-1312. doi:10.1093/ $\mathrm{cid} / \mathrm{cix} 1041$

141. Bouza E, Muñoz P, Burillo A. Role of the clinical microbiology laboratory in antimicrobial stewardship. Med Clin North Am. 2018;102(5):883-898. doi:10.1016/j.mena.2018.05.003

142. Ha TV, Nguyen AMT, Nguyen HST. Public awareness about antibiotic use and resistance among residents in highland areas of Vietnam. Biomed Res Int. 2019;2019:9398536. doi:10.1155/ 2019/9398536

143. Li B, Webster TJ. Bacteria antibiotic resistance: new challenges and opportunities for implant-associated orthopedic infections. $J$ Orthop Res. 2018;36(1):22-32. doi:10.1002/jor.23656

144. Maurer FP, Christner M, Hentschke M, Rohde H. Advances in rapid identification and susceptibility testing of bacteria in the clinical microbiology laboratory: implications for patient care and antimicrobial stewardship programs. Infect Dis Rep. 2017;9 (1):6839. doi:10.4081/idr.2017.6839

145. Clinical and Laboratory Standards Institute (CLSI). Performance Standards for Antimicrobial Susceptibility Testing; Twenty-Fourth Informational Supplement. CLSI Document M100-S24, Wayne; 2014.

146. Schulz LT, Fox BC, Polk RE. Can the antibiograms be used to assess microbiologic outcomes after antimicrobial stewardship interventions? A critical review of the literature. Pharmacotherapy. 2012;32 (8):668-676. doi:10.1002/j.1875-9114.2012.01163

147. Pakyz AL. The utility of hospital antibiograms as tools for guiding empiric therapy and tracking resistance. Insights from the Society of Infectious Diseases Pharmacists. Pharmacotherapy. 2007;27(9):1306-1312. doi:10.1592/phco.27.9.1306

148. Kållberg C, Årdal C, Salvesen Blix H, Klein E. Introduction and geographic availability of new antibiotics approved between 1999 and 2014. PLoS One. 2018;13(10):e0205166. doi:10.1371/journal.pone. 0205166

149. Morency-Potvin P, Schwartz DN, Weinstein RA. Antimicrobial stewardship: how the microbiology laboratory can right the ship. Clin Microbiol Rev. 2016;30(1):381-407. doi:10.1128/CMR.00066-16

150. Reed EE, Stevenson KB, West JE, Bauer KA, Goff DA. Impact of formulary restriction with prior authorization by an antimicrobial stewardship program. Virulence. 2013;4(2):158-162. doi:10.4161/ viru. 21657

151. LaRosa LA, Fishman NO, Lautenbach E, Koppel RJ, Morales $\mathrm{KH}$, Linkin DR. Evaluation of antimicrobial therapy orders circumventing an antimicrobial stewardship program: investigating the strategy of "stealth dosing". Infect Control Hosp Epidemiol. 2007;28(5):551-556. doi:10.1086/513535

152. Kumar A, Roberts D, Wood KE, et al. Duration of hypotension before initiation of effective antimicrobial therapy is the critical determinant of survival in human septic shock. Crit Care Med. 2006;34(6):1589-1596. doi:10.1097/01.CCM.0000217961

153. Kumar A. Optimizing antimicrobial therapy in sepsis and septic shock. Crit Care Clin. 2009;25(4):733-51, viii. doi:10.1016/j. ccc.2009.08.004

154. World Organization for Animal Health (OIE). OIE list of antimicrobials of veterinary importance; 2015. Available from: http://www.oie.int/fileadmin/Home/eng/Our_scientific_exper tise/docs/pdf/Eng_OIE_List_antimicrobials_May2015.pdf. Accessed December 9, 2020. 
155. Horikoshi Y, Suwa J, Higuchi H, et al. Sustained pediatric antimicrobial stewardship program with consultation to infectious diseases reduced carbapenem resistance and infection-related mortality. Int $J$ Infect Dis. 2017;64:69-73. doi:10.1016/j. ijid.2017.09.012

156. Wang $H$, Wang $H$, Yu X, et al. Impact of antimicrobial stewardship managed by clinical pharmacists on antibiotic use and drug resistance in a Chinese hospital, 2010-2016: a retrospective observational study. BMJ Open. 2019;9(8):e026072. doi:10.11 36/bmjopen-2018-026072

157. Wu JH, Langford BJ, Daneman N, Friedrich JO, Garber G. Antimicrobial stewardship programs in long-term care settings: a meta-analysis and systematic review. J Am Geriatr Soc. 2019;67 (2):392-399. doi:10.1111/jgs.15675

158. Nathwani D, Varghese D, Stephens J, Ansari W, Martin S, Charbonneau C. Value of hospital antimicrobial stewardship programs [ASPs]: a systematic review. Antimicrob Resist Infect Control. 2019;8:35. doi:10.1186/s13756-019-0471-0

159. Akpan MR, Isemin NU, Udoh AE, Ashiru-Oredope D. Implementation of antimicrobial stewardship programs in African countries: a systematic literature review. $J$ Glob Antimicrob Resist. 2020;22:317-324. doi:10.1016/j.jgar.2020. 03.009

160. Lee CF, Cowling BJ, Feng S, et al. Impact of antibiotic stewardship programs in Asia: a systematic review and meta-analysis. $J$ Antimicrob Chemother. 2018;73(4):844-851. doi:10.1093/jac/ $\mathrm{dkx} 492$

161. Xiao Y, Shen P, Zheng B, Zhou K, Luo Q, Li L. Change in antibiotic use in secondary and tertiary hospitals nationwide after a national antimicrobial stewardship campaign was launched in China, 2011-2016: an observational study. J Infect Dis. 2020;221(Supplement_2):S148-S155. doi:10.1093/infdis/jiz556

162. Mardani M, Abolghasemi S, Shabani S. Impact of an antimicrobial stewardship program in the antimicrobial-resistant and prevalence of clostridioides difficile infection and amount of antimicrobial consumed in cancer patients. BMC Res Notes. 2020;13(1):246. doi:10.1186/s13104-020-05085-3

163. Onorato L, Macera M, Calò F, et al. The effect of an antimicrobial stewardship program in two intensive care units of a teaching hospital: an interrupted time series analysis. Clin Microbiol Infect. 2020;26(6):782.e1-782.e6. doi:10.1016/j.cmi.2019.10.021

164. Savoldi A, Foschi F, Kreth F, et al. Impact of implementing a non-restrictive antibiotic stewardship program in an emergency department: a four-year quasi-experimental prospective study. Sci Rep. 2020;10(1):8194. doi:10.1038/s41598-020-65222-7

165. Singh S, Menon VP, Mohamed ZU, et al. Implementation and impact of an antimicrobial stewardship program at a tertiary care center in South India. Open Forum Infect Dis. 2018;6(4):ofy290. doi:10.1093/ofid/ofy290

166. Wee LE, Chung SJ, Tang SLS, et al. Who listens, and who doesn't? Factors associated with adherence to antibiotic stewardship intervention in a Singaporean tertiary hospital. $J$ Glob Antimicrob Resist. 2020;22:391-397. doi:10.1016/j.jgar.2020. 04.006

167. Abubakar U, Syed Sulaiman SA, Adesiyun AG. Impact of pharmacist-led antibiotic stewardship interventions on compliance with surgical antibiotic prophylaxis in obstetric and gynecologic surgeries in Nigeria. PLoS One. 2019;14(3):e0213395. doi:10.13 71/journal.pone.0213395

168. Brink AJ, Messina AP, Feldman C, Richards GA, van den Bergh D. Netcare Antimicrobial Stewardship Study Alliance. From guidelines to practice: a pharmacist-driven prospective audit and feedback improvement model for perioperative antibiotic prophylaxis in 34 South African hospitals. J Antimicrob Chemother. 2017;72(4):1227-1234. doi:10.1093/jac/dkw523
169. D'Agata EMC, Lindberg CC, Lindberg CM, et al. The positive effects of an antimicrobial stewardship program targeting outpatient hemodialysis facilities. Infect Control Hosp Epidemiol. 2018;39(12):1400-1405. doi:10.1017/ice.2018.237

170. Majumder MAA, Singh K, Hilaire MG, Rahman S, Sa B, Haque M. Tackling antimicrobial resistance by promoting antimicrobial stewardship in medical and allied health professional curricula. Expert Rev Anti Infect Ther. 2020;1-14. doi:10.1080/ 14787210.2020 .1796638

171. Minen MT, Duquaine D, Marx MA, Weiss D. A survey of knowledge, attitudes, and beliefs of medical students concerning antimicrobial use and resistance. Microb Drug Resist. 2010;16 (4):285-289. doi:10.1089/mdr.2010.0009

172. Castro-Sánchez E, Drumright LN, Gharbi M, Farrell S, Holmes AH. Mapping antimicrobial stewardship in undergraduate medical, dental, pharmacy, nursing, and veterinary education in the United Kingdom. PLoS One. 2016;11(2):e0150056. doi:10.1371/ journal.pone.0150056

173. Abbo LM, Cosgrove SE, Pottinger PS, et al. Medical students' perceptions and knowledge about antimicrobial stewardship: how are we educating our future prescribers? Clin Infect Dis. 2013;57 (5):631-638. doi:10.1093/cid/cit370

174. Pulcini C, Wencker F, Frimodt-Møller N, et al. European survey on principles of prudent antibiotic prescribing teaching in undergraduate students. Clin Microbiol Infect. 2015;21(4):354-361. doi:10.1016/j.cmi.2014.11.015

175. MacDougall C, Schwartz BS, Kim L, Nanamori M, Shekarchian $\mathrm{S}$, Chin-Hong PV. An interprofessional curriculum on antimicrobial stewardship improves knowledge and attitudes toward appropriate antimicrobial use and collaboration. Open Forum Infect Dis. 2017;4(1):ofw225. doi:10.1093/ofid/ofw225

176. Australian Commission on Safety and Quality in Health Care. Antimicrobial Stewardship in Australian Health Care. Sydney: ACSQHC; 2018.

177. Rocha-Pereira N, Lafferty N, Nathwani D. Educating healthcare professionals in antimicrobial stewardship: can online-learning solutions help? J Antimicrob Chemother. 2015;70(12):31753177. doi:10.1093/jac/dkv336

178. Lucas B. G7 and G20 Commitments on Health. K4D Helpdesk Report 673. Brighton, UK: Institute of Development Studies; 2019.

179. World Health Organization. Additional global, regional, and national strategies and plans to address antimicrobial resistance; 2014. Available from: https://www.who.int/antimicrobial-resis tance/global-action-plan/General_and_national_plans_amr_Dec_ 2014.pdf?ua=1. Accessed December 9, 2020.

180. Centers for Disease Control and Prevention. U.S. national action plan for combating antibiotic-resistant bacteria (National Action Plan); 2015. Available from: https://www.cdc.gov/drugresistance/us-activ ities/national-action-plan.html. Accessed December 9, 2020.

181. European Commission. EU action on antimicrobial resistance. Available from: https://ec.europa.eu/health/antimicrobial-resistance/ eu-action-on-antimicrobial-resistance_en. Accessed December 9, 2020.

182. World Health Organization. Countries step up to tackle antimicrobial resistance; 2018. Available from: https://www.who.int/ news-room/detail/18-07-2018-countries-step-up-to-tackle-antimi crobial-resistance. Accessed December 9, 2020.

183. Madero CM, Navas AL, Leon EP, Alvarez SS. Use of antibiotics with ONE HEALTH perspective: Spanish strategic action plan to reduce the risk of selection and dissemination of antibiotic resistance. Small Rumin Res. 2016;142:44-47.

184. Lammie SL, Hughes JM. Antimicrobial resistance, food safety, and one health: the need for convergence. Annu Rev Food Sci Technol. 2016;7:287-312. doi:10.1146/annurev-food-041715-033 251 
185. Shariff M. Antimicrobial resistance: challenges and the way forward. Indian J Chest Dis Allied Sci. 2016;58(3):157-159.

186. Holmes AH, Moore LS, Sundsfjord A, et al. Understanding the mechanisms and drivers of antimicrobial resistance. Lancet 2016;387(10014):176-187. doi:10.1016/S0140-6736(15)00473-0

187. Jacobs TG, Robertson J, van den Ham HA, Iwamoto K, Bak Pedersen H, Mantel-Teeuwisse AK. Assessing the impact of law enforcement to reduce over-the-counter (OTC) sales of antibiotics in low- and middle-income countries; a systematic literature review. BMC Health Serv Res. 2019;19(1):536. doi:10.1186/ s12913-019-4359-8

188. Zhao Y, Li G, Chen Y, Lu Y. Challenges and advances in genome editing technologies in streptomyces. Biomolecules. 2020;10 (5):734.

189. Gholizadeh P, Köse Ş, Dao S, et al. How CRISPR-Cas system could be used to combat antimicrobial resistance. Infect Drug Resist. 2020;13:1111-1121. doi:10.2147/IDR.S247271

190. Goren M, Yosef I, Qimron U. Sensitizing pathogens to antibiotics using the CRISPR-Cas system. Drug Resist Updates. 2017;30:16. doi:10.1016/j.drup.2016.11.003

191. Yao R, Liu D, Jia X, Zheng Y, Liu W, Xiao Y. CRISPR-Cas9/ Cas12a biotechnology and application in bacteria. Synth Syst Biotechnol. 2018;3(3):135-149. doi:10.1016/j.synbio.2018.09. 004

192. Aslam B, Rasool M, Idris A, et al. CRISPR-Cas system: a potential alternative tool to cope antibiotic resistance. Antimicrob Resis Infect Control. 2020;9:131. doi:10.1186/ s13756-020-00795-6

193. Barrangou R, Fremaux C, Deveau H, et al. CRISPR provides acquired resistance against viruses in prokaryotes. Science. 2007;315(5819):1709-1712.

194. Müller V, Rajer F, Frykholm K, et al. Direct identification of antibiotic resistance genes on single plasmid molecules using CRISPR/Cas9 in combination with optical DNA mapping. Sci Rep. 2016;6:37938. doi:10.1038/srep37938

195. Touchon M, Charpentier S, Pognard D, et al. Antibiotic resistance plasmids spread among natural isolates of Escherichia coli in spite of CRISPR elements. Microbiology. 2012;158(12):29973004. doi:10.1099/mic.0.060814-0

196. Bikard D, Euler CW, Jiang W, et al. Exploiting CRISPR-Cas nucleases to produce sequence-specific antimicrobials. Nat Biotechnol. 2014;32:1146. doi:10.1038/nbt.3043

197. Hale Caryn R, Majumdar S, Elmore J, et al. Essential features and rational design of CRISPR RNAs that function with the Cas RAMP module complex to cleave RNAs. Mol Cell. 2012;45 (3):292-302. doi:10.1016/j.molcel.2011.10.023

198. Cui L, Bikard D. Consequences of Cas9 cleavage in the chromosome of Escherichia coli. Nucleic Acids Res. 2016;44(9):42434251.

199. Law BJC, Zhuo Y, Winn M, et al. A vitamin K-dependent carboxylase orthologue is involved in antibiotic biosynthesis. Nat Catalysis. 2018;1(12):977-984. doi:10.1038/s41929-018-0178-2

200. Van Der Oost J, Westra ER, Jackson RN, Wiedenheft B. Unravelling the structural and mechanistic basis of CRISPRCas systems. Nat Rev Microbiol. 2014;12(7):479-492.

201. Citorik RJ, Mimee M, Lu TK. Sequence-specific antimicrobials using efficiently delivered RNA-guided nucleases. Nat Biotechnol. 2014;32:1141. doi:10.1038/nbt.3011

202. Vercoe RB, Chang JT, Dy RL, et al. Cytotoxic chromosomal targeting by CRISPR/Cas systems can reshape bacterial genomes and expel or remodel pathogenicity islands. PLoS Genet. 2013;9 (4):e1003454. doi:10.1371/journal.pgen.1003454

203. Harmsen IA, Mollema L, Ruiter RA, Paulussen TG, de Melker HE, Kok G. Why parents refuse childhood vaccination: a qualitative study using online focus groups. BMC Public Health. 2013;13:1183. doi:10.1186/1471-2458-13-1183
204. Jansen KU, Anderson AS. The role of vaccines in fighting antimicrobial resistance (AMR). Hum Vaccin Immunother. 2018;14 (9):2142-2149. doi:10.1080/21645515.2018.1476814

205. Lima T, Domingues S, DaSilva GJ. Plasmid-medicated colistin resistance in samonella enterica: a review. Microorganisms. 2019;7(2):55. doi:10.3390/microorganisms 7020055

206. World Health Organization. World Health Organization list of critically important antimicrobials (CIA), 3rd revision; 2011. Available from: http://www.who.int/foodsafety/publications/anti microbials-third/en. Accessed December 9, 2020.

207. Mshana SE, Matee M, Rweyemamu M. Antimicrobial resistance in human and animal pathogens in Zambia, Democratic Republic of Congo, Mozambique, and Tanzania: an urgent need of a sustainable surveillance system. Ann Clin Microbiol Antimicrob. 2013;12:28. doi:10.1186/1476-0711-12-28

208. Davis ME, Liu TL, Taylor YJ, et al. Exploring patient awareness and perceptions of the appropriate use of antibiotics: a mixedmethods study. Antibiotics (Basel). 2017;6(4):23. doi:10.3390/ antibiotics6040023

209. Pearson M, Chandler C. Knowing antimicrobial resistance in practice: a multi-country qualitative study with human and animal healthcare professionals. Glob Health Action. 2019;12 (1):1599560. doi:10.1080/16549716.2019.1599560

210. Michael CA, Dominey-Howes D, Labbate M. The antimicrobial resistance crisis: causes, consequences, and management. Front Public Health. 2014;2:145. doi:10.3389/fpubh.2014.00145

211. Lomazzi M, Moore M, Johnson A, Balasegaram M, Borisch B. Antimicrobial resistance - moving forward? BMC Public Health. 2019;19(1):858. doi:10.1186/s12889-019-7173-7

212. Founou RC, Founou LL, Essack SY. Clinical and economic impact of antibiotic resistance in developing countries: a systematic review and meta-analysis. PLoS One. 2017;12(12):e0189621. doi:10.1371/journal.pone.0189621

213. Alsan M, Schoemaker L, Eggleston K, Kammili N, Kolli P, Bhattacharya J. Out-of-pocket health expenditures and antimicrobial resistance in low-income and middle-income countries: an economic analysis. Lancet Infect Dis. 2015;15(10):1203-1210. doi:10.1016/S1473-3099

214. O'Neill J Review on antimicrobial resistance antimicrobial resistance: tackling a crisis for the health and wealth of nations. London: Review on Antimicrobial Resistance; 2014. Available from: https://amr-review.org/sites/default/files/AMR\%20Review $\% 20$ Paper $\% 20$ - $\% 20$ Tackling $\% 20$ a $\% 20$ crisis $\% 20$ for $\% 20$ the $\%$ 20health\%20and\%20wealth\%20of\%20nations_1.pdf. Accessed December 9, 2020

215. de Kraker ME, Stewardson AJ, Harbarth S. Will 10 million people die a year due to antimicrobial resistance by 2050 ? PLoS Med. 2016;13(11):e1002184. doi:10.1371/journal.pmed.1002184

216. Wilson K, Gardam M, McDougall C, Attaran A, Upshur R. WHO's response to global public health threats: XDR-TB. PLoS Med. 2007;4(7):e246. doi:10.1371/journal.pmed.0040246

217. Laxminarayan R, Bhutta Z, Duse A, et al. Drug Resistance. Jamison DT, Breman JG, Measham AR, et al. editors. Disease Control Priorities in Developing Countries. 2nd. Washington (DC):The International Bank for Reconstruction and Development/The World Bank; 2006

218. Abadi TBA, Rizvanov AA, Haertlé T, et al. World Health Organization report: current crisis of antibiotic resistance. BioNanoSci. 2019;9:778-788. doi:10.1007/s12668-019-00658-4

219. Rather IA, Kim BC, Bajpai VK, Park YH. Self-medication and antibiotic resistance: crisis, current challenges, and prevention. Saudi J Biol Sci. 2017;24(4):808-812. doi:10.1016/j.sjbs.2017.01.004

220. Ayukekbong JA, Ntemgwa M, Atabe AN. The threat of antimicrobial resistance in developing countries: causes and control strategies. Antimicrob Resist Infect Control. 2017;6:47. doi:10. 1186/s13756-017-0208-x 
221. Kelesidis T, Falagas ME. Substandard/counterfeit antimicrobial drugs. Clin Microbiol Rev. 2015;28(2):443-464. doi:10.1128/ CMR.00072-14

222. Almuzaini T, Choonara I, Sammons H. Substandard and counterfeit medicines: a systematic review of the literature. BMJ Open. 2013;3(8):e002923. doi:10.1136/bmjopen-2013-002923

223. Ozawa S, Evans DR, Bessias S, et al. Prevalence and estimated economic burden of substandard and falsified medicines in lowand middle-income countries: a systematic review and meta-analysis. JAMA Netw Open. 2018;1(4):e181662. doi:10.1001/ jamanetworkopen.2018.1662

224. Fayzrakhmanov NF. Fighting trafficking of falsified and substandard medicinal products in Russia. Int J Risk Saf Med. 2015;27 (Suppl 1):S37-S40. doi:10.3233/JRS-150681

225. Mackey TK. Prevalence of substandard and falsified essential medicines: still an incomplete picture. JAMA Netw Open. 2018;1(4):e181685. doi:10.1001/jamanetworkopen.2018.1685

226. Mathur P, Singh S. Multidrug resistance in bacteria: a serious patient safety challenge for India. J Lab Physicians. 2013;5(1):510. doi:10.4103/0974-2727.115898

227. Steinig EJ, Duchene S, Robinson DA, et al. Evolution and global transmission of a multidrug-resistant, community-associated methicillin-resistant staphylococcus aureus lineage from the indian subcontinent. mBio. 2019;10(6):e01105-e01119. doi:10.11 28/mBio.01105-19

228. Tarai B, Das P, Kumar D. Recurrent challenges for clinicians: emergence of methicillin-resistant staphylococcus aureus, vancomycin resistance, and current treatment options. J Lab Physicians. 2013;5(2):71-78. doi:10.4103/0974-2727.119843

229. Conly J, Johnston B. Where are all the new antibiotics? The new antibiotic paradox. Can J Infect Dis Med Microbiol. 2005;16 (3):159-160. doi:10.1155/2005/892058

230. Institute of Medicine (US) Forum on Emerging Infections; Knobler SL, Lemon SM, Najafi M, et al. The resistance phenomenon in microbes and infectious disease vectors: implications for human health and strategies for containment: workshop summary. 7. Strategies to contain the development and consequences of resistance. Washington (DC): National Academies Press (US); 2003. Available from: https://www.ncbi.nlm.nih.gov/books/ NBK97144/. Accessed December 9, 2020.

231. Dhingra S, Rahman NAA, Peile E, et al. Microbial resistance movements: an overview of global public health threats posed by antimicrobial resistance, and how best to counter. Front Public Health. 2020. doi:10.3389/fpubh.2020.535668

232. Cosgrove SE. The relationship between antimicrobial resistance and patient outcomes: mortality, length of hospital stays, and health care costs. Clin Infect Dis. 2006;42(Suppl 2):S82-S89. doi:10.1086/499406

233. Maragakis LL, Perencevich EN, Cosgrove SE. Clinical and economic burden of antimicrobial resistance. Expert Rev Anti Infect Ther. 2008;6(5):751-763. doi:10.1586/14787210.6.5.751

234. Frost I, Van Boeckel TP, Pires J, Craig J, Laxminarayan R. Global geographic trends in antimicrobial resistance: the role of international travel. J Travel Med. 2019;26(8):taz036. doi:10.1093/jtm/ taz036

235. Ebrahim M, Gravel D, Thabet C, Abdesselam K, Paramalingam $\mathrm{S}$, Hyson C. Antimicrobial use and antimicrobial resistance trends in Canada: 2014. Can Commun Dis Rep. 2016;42(11):227-231. doi: $10.14745 / \mathrm{ccdr}$

236. Woon SA, Fisher D. Antimicrobial agents - optimizing the ecological balance. BMC Med. 2016;14(1):114. doi:10.1186/s12916016-0661-z

237. Luepke KH, Suda KJ, Boucher H, et al. 3rd. past, present, and future of antibacterial economics: increasing bacterial resistance, limited antibiotic pipeline, and societal implications. Pharmacotherapy. 2017;37(1):71-84. doi:10.1002/phar.1868
238. World Health Organization. Antimicrobial resistance. Key Facts; 2020. Available from: https://www.who.int/news-room/factsheets/detail/antimicrobial-resistance\#: : text=Antimicrobial\% 20resistance $\% 20$ (AMR)\%20threatens\%20the, all\%20government \%20sectors\%20and\%20society. Accessed December 9, 2020.

239. Centers for Disease Control and Prevention. Antibiotic prescribing and use in hospitals and long-term care. Core elements of hospital antibiotic stewardship programs; 2017. Available from: www.cdc.gov/antibiotic-use/healthcare/implementation/core-ele ments.html\#_ENREF_57. Accessed December 9, 2020.

240. Pollack LA, Srinivasan A. Core elements of hospital antibiotic stewardship programs from the centers for disease control and prevention. Clin Infect Dis. 2014;59(Suppl 3):S97-S100. doi: $10.1093 / \mathrm{cid} / \mathrm{ciu} 542$

241. Ohl CA, Dodds Ashley ES. Antimicrobial stewardship programs in community hospitals: the evidence base and case studies. Clin Infect Dis. 2011;53(Suppl 1):S23-S28; quiz S29-S30. doi:10.10 93/cid/cir365

242. File TM, Solomkin JS, Cosgrove SE. Strategies for improving antimicrobial use and the role of antimicrobial stewardship programs. Clin Infect Dis. 2011;53(Suppl 1):S15-S22. doi:10.1093/ $\mathrm{cid} / \mathrm{cir} 364$

243. Haque M, McKimm J, Sartelli M, et al. Strategies to prevent healthcare-associated infections: a narrative overview. Risk Manag Healthc Policy. 2020;13:1765-1780. doi:10.2147/RMHP. S269315

244. Baroudi R, Flaugher M, Grace E, Zakria D. The importance of an antimicrobial stewardship program. Fed Pract. 2015;32(9):20-24.

245. Rhee SM, Stone ND. Antimicrobial stewardship in long-term care facilities. Infect Dis Clin North Am. 2014;28(2):237-246. doi:10.1016/j.idc.2014.01.001

246. Goldman JL, Newland JG. New horizons for pediatric antibiotic stewardship. Infect Dis Clin North Am. 2015;29(3):503-511. doi:10.1016/j.idc.2015.05.003

247. Barlam TF, Cosgrove SE, Abbo LM, et al. Implementing an antibiotic stewardship program: guidelines by the Infectious Diseases Society of America and the Society for Healthcare Epidemiology of America. Clin Infect Dis. 2016;62(10):e51e77. doi:10.1093/cid/ciw118

248. Centers for Disease Control and Prevention. Core elements of hospital antibiotic stewardship programs. Atlanta, GA: US Department of Health and Human Services, CDC; 2019. Available from: https://www.cdc.gov/antibiotic-use/core-ele ments/hospital.html. Accessed December 9, 2020.

249. Buckel WR, Veillette JJ, Vento TJ, Stenehjem E. Antimicrobial stewardship in community hospitals. Med Clin North Am. 2018;102(5):913-928. doi:10.1016/j.mcna.2018.05.005

250. Shallcross LJ, Howard SJ, Fowler T, Davies SC. Tackling the threat of antimicrobial resistance: from policy to sustainable action. Philos Trans $R$ Soc Lond B Biol Sci. 2015;370 (1670):20140082. doi:10.1098/rstb.2014.0082

251. Hegewisch-Taylor J, Dreser-Mansilla A, Romero-Mónico J, Levy-Hara G. Antimicrobial stewardship in hospitals in Latin America and the Caribbean: a scoping review. Rev Panam Salud Publica. 2020;44:e68. doi:10.26633/RPSP.2020.68

252. Resman F. Antimicrobial stewardship programs; a two-part narrative review of step-wise design and issues of controversy Part I: step-wise design of an antimicrobial stewardship program. Ther Adv Infect Dis. 2020;7:2049936120933187. doi:10.1177/204993 6120933187

253. Leuthner KD, Doern GV. Antimicrobial stewardship programs. J Clin Microbiol. 2013;51(12):3916-3920. doi:10.1128/JCM.01751-13

254. Ho PL, Cheng JC, Ching PT, et al. Optimizing antimicrobial prescription in hospitals by introducing an antimicrobial stewardship program in Hong Kong: a consensus statement. Hong Kong Med J. 2006;12(2):141-148. 
255. Lee CR, Cho IH, Jeong BC, Lee SH. Strategies to minimize antibiotic resistance. Int J Environ Res Public Health. 2013;10 (9):4274-4305. doi:10.3390/ijerph10094274

256. Lee CR, Lee JH, Kang LW, Jeong BC, Lee SH. Educational effectiveness, target, and content for prudent antibiotic use. Biomed Res Int. 2015;2015:214021. doi:10.1155/2015/ 214021

257. Goff DA. Antimicrobial stewardship: bridging the gap between quality care and cost. Curr Opin Infect Dis. 2011;24(Suppl 1):S11-S20. doi:10.1097/01.qco.0000393484. 17894.05

258. Collignon PJ, McEwen SA. One health-its importance in helping to better control antimicrobial resistance. Trop Med Infect Dis. 2019;4(1):22. doi:10.3390/tropicalmed4010022

259. Lipsitch M, Siber GR. How can vaccines contribute to solving the antimicrobial resistance problem? mBio. 2016;7(3):e00428 e00416. doi:10.1128/mBio.00428-16

260. Kelly R, Zoubiane G, Walsh D, Ward R, Goossens H. Public funding for research on antibacterial resistance in the JPIAMR countries, the European Commission, and related European Union agencies: a systematic observational analysis. Lancet Infect Dis. 2016;16(4):431-440. doi:10.1016/S1473-3099(15) 00350-3

261. Bragginton EC, Piddock LJ. UK and European Union public and charitable funding from 2008 to 2013 for bacteriology and antibiotic research in the UK: an observational study. Lancet Infect Dis. 2014;14(9):857-868. doi:10.1016/S1473-3099(14) 70825-4

262. Joint Programming Initiative on Antimicrobial Resistance, JPIAMR. Strategic research and innovation agenda on antimicrobial resistance. Available from: https://www.jpiamr.eu/wpcontent/uploads/2019/05/JPIAMR_SRIA_final.pdf. Accessed December 9, 2020.

263. Carrico RM, Garrett H, Balcom D, Glowicz JB. Infection prevention and control core practices: a roadmap for nursing practice. Nursing. 2018;48(8):28-29. doi:10.1097/01.NURSE. 0000544318

264. Rogers Van Katwyk S, Jones SL, Hoffman SJ. Mapping educational opportunities for healthcare workers on antimicrobial resistance and stewardship around the world. Hum Resour Health. 2018;16(1):9. doi:10.1186/s12960-018-0270-3

265. Haque M, Rahman NAA, McKimm J, et al. Self-medication of antibiotics: investigating practice among university students at the Malaysian National Defence University. Infect Drug Resist. 2019;12:1333-1351. doi:10.2147/IDR.S203364

266. Haque M, Rahman NAA, McKimm J, et al. A cross-sectional study evaluating the knowledge and beliefs about and the use of antibiotics amongst Malaysian university students. Expert Rev Anti Infect Ther. 2019;17(4):275-284. doi:10.1080/14787210.20 19.1581607

267. Woolf SH, Grol R, Hutchinson A, Eccles M, Grimshaw J. Clinical guidelines: potential benefits, limitations, and harms of clinical guidelines. BMJ. 1999;318(7182):527-530. doi:10.1136/ bmj.318.7182.527

268. Weisz G, Cambrosio A, Keating P, Knaapen L, Schlich T, Tournay VJ. The emergence of clinical practice guidelines. Milbank Q. 2007;85(4):691-727. doi:10.1111/j.14 68-0009.2007
269. Anderson AD, McClellan J, Rossiter S, et al.Public health consequences of use of antimicrobial agents in agriculture. Knobler $\mathrm{SL}$, Lemon SM, Najafi $\mathrm{M}$, et al. editors. The Resistance Phenomenon in Microbes and Infectious Disease Vectors: Implications for Human Health and Strategies for Containment: Workshop Summary. Washington (DC):National Academies Press (US); 2003

270. Llor C, Bjerrum L. Antimicrobial resistance: risk associated with antibiotic overuse and initiatives to reduce the problem. Ther $A d v$ Drug Saf. 2014;5(6):229-241. doi:10.1177/2042098614554919

271. Pulcini C, Gyssens IC. How to educate prescribers in antimicrobial stewardship practices? Virulence. 2013;4(2):192-202. doi:10.4161/viru.23706

272. Silverberg SL, Zannella VE, Countryman D, et al. A review of antimicrobial stewardship training in medical education. Int $J$ Med Educ. 2017;8:353-374. doi:10.5116/ijme.59ba.2d47

273. Gyssens IC. Role of education in antimicrobial stewardship. Med Clin North Am. 2018;102(5):855-871. doi:10.1016/j.mcna.2018. 05.011

274. Marshall BM, Levy SB. Food animals and antimicrobials: impacts on human health. Clin Microbiol Rev. 2011;24(4):718733. doi:10.1128/CMR.00002-11

275. Economou V, Gousia P. Agriculture, and food animals as a source of antimicrobial-resistant bacteria. Infect Drug Resist. 2015;8:4961. doi:10.2147/IDR.S55778

276. McDermott PF, Zhao S, Wagner DD, Simjee S, Walker RD, White DG. The food safety perspective of antibiotic resistance. Anim Biotechnol. 2002;13(1):71-84. doi:10.1081/ABIO-1200 05771

277. Mathew AG, Cissell R, Liamthong S. Antibiotic resistance in bacteria associated with food animals: a United States perspective of livestock production. Foodborne Pathog Dis. 2007;4(2):115133. doi: $10.1089 /$ fpd. 2006.0066

278. Moralejo D, El Dib R, Prata RA, Barretti P, Corrêa I. Improving adherence to Standard Precautions for the control of healthcareassociated infections. Cochrane Database Syst Rev. 2018;2(2): CD010768. doi:10.1002/14651858.CD010768.pub2

279. WHO Guidelines on hand hygiene in health care: first global patient safety challenge clean care is safer care. Geneva: World Health Organization; 2009. Available from: https://www.ncbi. nlm.nih.gov/books/NBK144005/. Accessed December 9, 2020.

280. Houghton C, Meskell P, Delaney H, et al. Barriers and facilitators to healthcare workers' adherence with infection prevention and control (IPC) guidelines for respiratory infectious diseases: a rapid qualitative evidence synthesis. Cochrane Database Syst Rev. 2020;4(4):CD013582. doi:10.1002/14651858.CD013582

281. Verbeek JH, Rajamaki B, Ijaz S, et al. Personal protective equipment for preventing highly infectious diseases due to exposure to contaminated body fluids in healthcare staff. Cochrane Database Syst Rev. 2020;5:CD011621. doi:10.1002/14651858.CD011621. pub5

282. Haque M, Sartelli M, McKimm J, Abu Bakar M. Healthcareassociated infections - an overview. Infect Drug Resist. 2018;11:2321-2333. doi:10.2147/IDR.S177247

283. Haque M. Handwashing in averting infectious diseases: relevance to COVID-19. J Popul Ther Clin Pharmacol. 2020;27(SPt 1): e37-e52. doi:10.15586/jptcp.v27SP1.711 


\section{Publish your work in this journal}

Infection and Drug Resistance is an international, peer-reviewed openaccess journal that focuses on the optimal treatment of infection (bacterial, fungal and viral) and the development and institution of preventive strategies to minimize the development and spread of resistance. The journal is specifically concerned with the epidemiology of antibiotic resistance and the mechanisms of resistance development and diffusion in both hospitals and the community. The manuscript management system is completely online and includes a very quick and fair peerreview system, which is all easy to use. Visit http://www.dovepress.com/ testimonials.php to read real quotes from published authors. 